“Apolar carbohydrates as DNA capping agents" Lucas, R., Vengut-Climent, E., Gómez-Pinto, I., Aviñó, A., Eritja, R., González, C., Morales, J.C. Chem Comm., 48, 2991-2993 (2012). Doi: 10.1039/C2CC17093K

\title{
Apolar carbohydrates as DNA capping agents
}

\author{
Ricardo Lucas, ${ }^{a}$ Empar Vengut-Climent, ${ }^{a}$ Irene Gómez-Pinto, ${ }^{b}$ Anna Aviñó, ${ }^{c}$ Ramón \\ Eritja, ${ }^{\mathrm{C}}$ Carlos González ${ }^{\mathrm{b}}$ and Juan C. Morales*,a \\ ${ }^{a}$ Instituto de Investigaciones Químicas, CSIC - Universidad de Sevilla, Américo Vespucio, \\ 49, 41092 Sevilla, Spain. E-mail: jcmorales@iiq.csic.es \\ b Instituto de Química Física 'Rocasolano', CSIC, C/. Serrano 119, 28006 Madrid, Spain \\ c Instituto de Investigación Biomédica de Barcelona, IQAC, CSIC, CIBER - BBN Networking \\ Centre on Bioengineering, Biomaterials and Nanomedicine, Baldiri Reixac 10, E-08028 \\ Barcelona, Spain
}

Dedicated to Professor Soledad Penadés on her 70th birthday.

Abstract. Mono- and disaccharides have been shown to stack on top of DNA duplexes stabilizing sequences with terminal $C-G$ base pairs. Here we present an apolar version of glucose and cellobiose as new capping agents that stack on DNA increasing considerably its stability with respect to their natural polyhydroxylated mono- and disaccharide DNA conjugates.

Non-covalent forces direct molecular interactions between biomolecules and their combination and interplay in biology rules life. DNA being the central molecule of life also gives the chance to study molecular interactions in aqueous media. Aromatic $\pi-\pi$ stacking interactions have extensively been studied using DNA as a model. Both natural ${ }^{1}$ and non-natural ${ }^{2-4}$ aromatic bases attached to the 30 -end or 50-end of double stranded DNA have shown enhanced stabilization of DNA duplexes, acting as capping agents. These molecular "caps" are usually planar aromatic rings of different size and shape that take advantage of $\pi-\pi$ stacking interactions. $^{5-8}$ The only non-planar compounds described to stack on DNA are steroids such as cholic acid which showed a high increase in DNA stability via $\mathrm{CH}-\pi$ interactions. ${ }^{9}$ Recently, binaphthyl and phenylcyclohexyl nucleosides ${ }^{10,11}$ with nonplanar aromatic bases have been included inside DNA but no data as capping entities were reported.

Our group has studied carbohydrate-aromatic stacking interactions using carbohydrate oligonucleotide conjugates (COCs) with dangling-ends as a model. First, we evaluated monosaccharide-phenyl interactions as a double dangling motif at the edge of a duplex of DNA. ${ }^{12}$ We found that stabilization varies from -0.15 to $0.40 \mathrm{kcal} \mathrm{mol}^{-1}$ and depends on the number of hydroxyl groups and stereochemistry. Recently, we have shown that highly polar carbohydrates can act as DNA capping molecules. Sugar stacking is observed for mono- and disaccharides on top of $\mathrm{C}-\mathrm{G}$ or $\mathrm{T}-\mathrm{A}$ base pairs as the edge of theDNAduplex. ${ }^{13}$ Nevertheless, stabilization of the DNA double helix is only observed with $C-G$ or $G-C$ terminal base pairs. 
Herein, we report the synthesis of oligonucleotides with permethylated monoand disaccharides covalently linked to their 50-end. These apolar carbohydrates act as new capping molecules capable of stacking on double-stranded DNA (Fig. 1). Permethylated glucose and cellobiose were found to stabilize DNA duplexes much more than natural glucose and cellobiose.

Synthesis of the permethylated carbohydrate oligonucleotide conjugates started with the preparation of the corresponding permethylated glucose and cellobiose phosphoramidite derivatives (5 and 10, respectively) (Scheme 1). Glycosylation of the O-benzyl protected ethylene glycol spacer followed by deprotection of the acetyl groups yielded intermediate 2. Methylation under standard conditions produced compound $\mathbf{3}$ in good overall yield (70\%, 3 steps). Further hydrogenation and standard phosphoramidite preparation proceeded uneventfully to yield permethylated glucose phosphoramidite $\mathbf{5}$ ( $76 \%, 2$ steps). A similar synthetic strategy was followed to prepare permethylated cellobiose phosphoramidite 10 ( $48 \%$ yield, 5 steps).

Preparation of the apolar saccharide oligonucleotide conjugates was carried out by standard solid phase oligonucleotide synthesis using compounds $\mathbf{5}$ or $\mathbf{1 0}$ at the last coupling step. Both apolar carbohydrates were attached to selfcomplementary sequences CGCGCG, GGCGCC, AGCGCT and TGCGCA. Solutions of the COCs were subjected to UV melting analysis and thermodynamic parameters were calculated (Table 1).

Conjugates containing permethylated glucose and cellobiose on sequences terminated on a $\mathrm{C}-\mathrm{G}$ base pair (conjugates $\mathbf{1 5}$ and 19) increased considerably their melting points $\left(7.8^{\circ} \mathrm{C}\right.$ and $8.3^{\circ} \mathrm{C}$, respectively) over those of the natural control sequence 11.

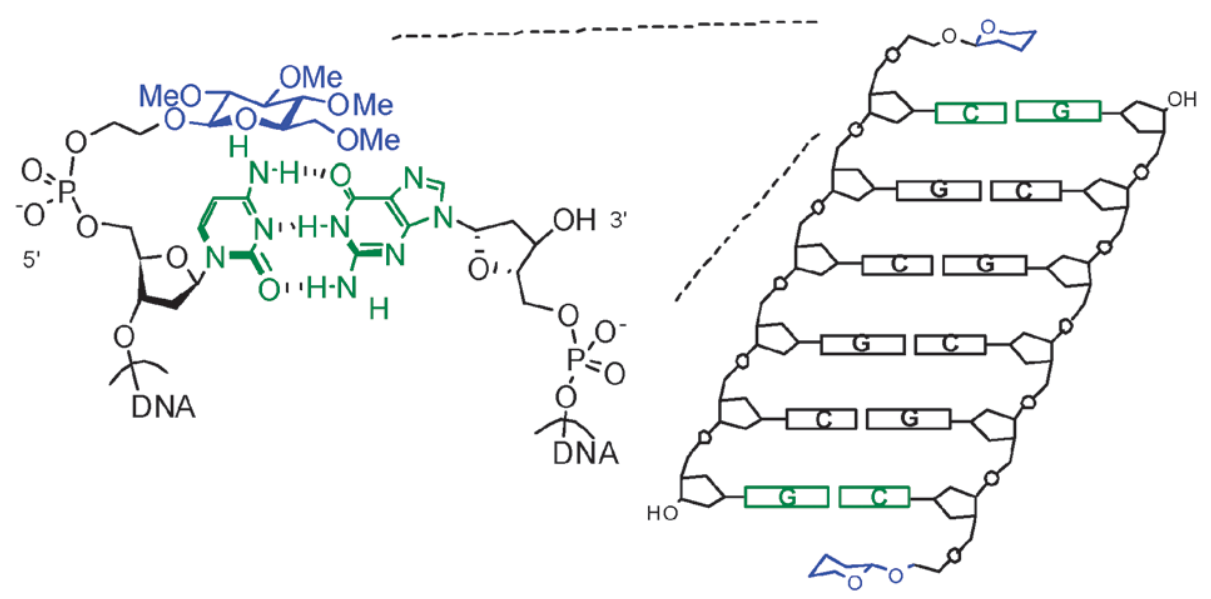

Fig. 1 Schematic drawing of COCs with dangling-ends and details of one of them (permethylated glucose stacking on top of a $\mathrm{C}-\mathrm{G}$ base pair). 


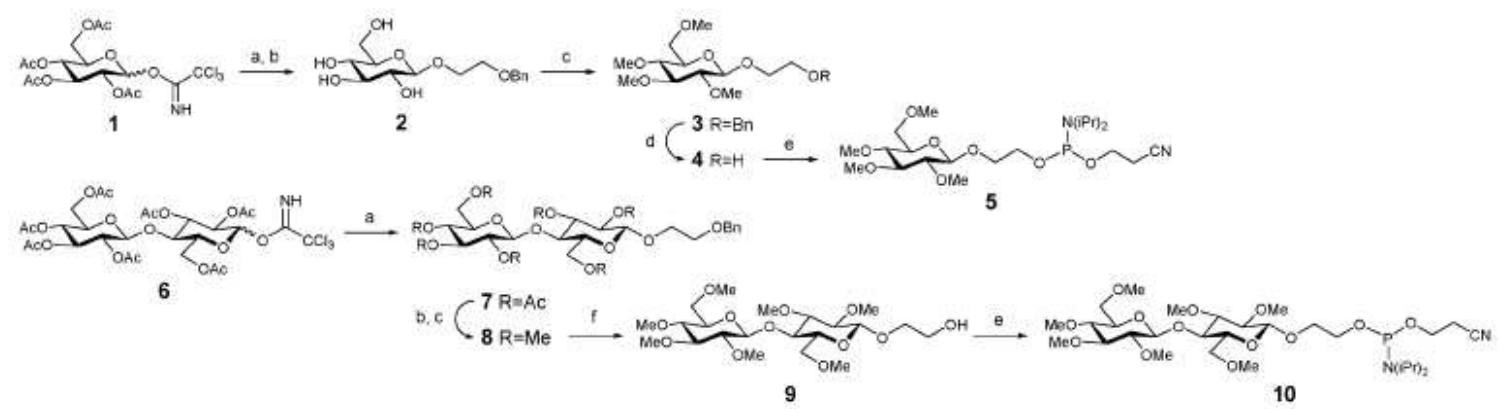

Scheme 1 Synthesis of permethylated glucose and cellobiose phosphoramidites $\mathbf{5}$ and $\mathbf{1 0 .}$ Reaction conditions: (a) $\mathrm{BnOCH}_{2} \mathrm{CH}_{2} \mathrm{OH}, \mathrm{BF}_{3}-\mathrm{OEt}_{2}, \mathrm{CH}_{2} \mathrm{Cl}_{2}$; (b) $\mathrm{Na}_{2} \mathrm{CO}_{3}, \mathrm{MeOH}$; (c) $\mathrm{MeI}, \mathrm{NaH}$, DMF; (d) $\mathrm{H}_{2}, \mathrm{Pd}(\mathrm{OH})_{2}, \mathrm{THF}-\mathrm{MeOH}$; (e) 2-cyanoethyl- $N, N^{\prime}$-diisopropylaminochlorophosphoramidite, DIEA, $\mathrm{CH}_{2} \mathrm{Cl}_{2} ;(\mathrm{f}) \mathrm{H}_{2}, \mathrm{Pd}(\mathrm{OH})_{2}$, AcOEt-MeOH.

Table 1. Thermodynamic parameters for COC's

\begin{tabular}{|c|c|c|c|c|c|}
\hline X-DNA sequences ${ }^{a, b, c, d}$ & $T_{m}{ }^{e} /{ }^{\circ} \mathrm{C}$ & $-\Delta H^{\circ}$ & $-\Delta S^{\circ}$ & $-\Delta G^{\mathrm{O}_{37}}$ & $-\Delta \Delta G^{\circ}{ }_{37}$ \\
\hline \multicolumn{6}{|l|}{$X=$ none $^{f}$} \\
\hline CGCGCG 11 & 40.9 & 46.5 & 123 & 8.2 & -- \\
\hline AGCGCT 12 & 33.5 & 40.3 & 107 & 7.1 & -- \\
\hline \multicolumn{6}{|l|}{$\mathrm{X}=$ glucose $-\mathrm{C} 2^{f}$} \\
\hline CGCGCG 13 & 44.0 & 52.1 & 140 & 8.7 & -0.5 \\
\hline AGCGCT 14 & 33.6 & 37.3 & 98 & 7.0 & 0.1 \\
\hline \multicolumn{6}{|l|}{$\mathrm{X}=\operatorname{glc}(\mathrm{Me})-\mathrm{C} 2^{f}$} \\
\hline CGCGCG 15 & 48.7 & 55.0 & 147 & 9.4 & -1.2 \\
\hline AGCGCT 16 & 34.5 & 44.8 & 121 & 7.2 & -0.2 \\
\hline \multicolumn{6}{|l|}{$X=$ cellobiose $-C 2^{f}$} \\
\hline CGCGCG 17 & 45.9 & 49.2 & 130 & 8.9 & -0.7 \\
\hline AGCGCT 18 & 34.4 & 39.1 & 103 & 7.1 & 0.0 \\
\hline \multicolumn{6}{|l|}{$\mathrm{X}=\operatorname{cellob}(\mathrm{Me})^{f}$} \\
\hline CGCGCG 19 & 49.2 & 55.0 & 146 & 9.7 & -1.5 \\
\hline AGCGCT $\mathbf{2 0}$ & 37.7 & 43.9 & 117 & 7.7 & -0.6 \\
\hline
\end{tabular}

${ }^{a}$-C2- states for $-\mathrm{CH}_{2}-\mathrm{CH}_{2}-\mathrm{OPO}_{2}{ }^{-}-{ }^{b}$ Buffer: $10 \mathrm{mM} \mathrm{Na}$ phosphate, $1 \mathrm{M} \mathrm{NaCl}$, pH 7.0. ${ }^{c}$ Estimated errors are: $T_{m} \pm 0.8{ }^{\circ} \mathrm{C}$ and $\pm 6 \%$ in $\Delta G^{\circ}$. ${ }^{d}$ Units for $\Delta H^{\circ}$ and $\Delta G^{\circ}$ are kcal mol ${ }^{-1}$ and for $\Delta S^{\circ}$ are cal $\mathrm{K}^{-1}$ $\mathrm{mol}^{-1} .{ }^{e}$ Average value of three experiments measured at $5 \mu \mathrm{M}$ conc. ${ }^{f}$ From ref. 13.

When conjugates with apolar glucose 15 and apolar cellobiose $\mathbf{1 9}$ are compared with their corresponding natural hydroxylated versions glucose-DNA conjugate 13 and cellobiose- DNA conjugate 17, $T_{m}$ 's are increased by $4.7{ }^{\circ} \mathrm{C}$ and $3.3{ }^{\circ} \mathrm{C}$, respectively. A similar trend is observed when $\Delta \mathrm{G}$ values are compared; conjugates 15 and 19 stabilize CGCGCG duplexes by -1.2 and $-1.5 \mathrm{kcal} \mathrm{mol}^{-1}$, respectively, with respect to unmodified CGCGCG. This stabilization is similar to that found for a benzene nucleoside in the same context. ${ }^{2}$ As a result, the duplex stabilizations of conjugates with the apolar version of glucose $\mathbf{1 5}$ and cellobiose $\mathbf{1 9}$ are 2.4 and 2.1 times more stable, respectively, than their corresponding conjugates with natural glucose $\mathbf{1 3}$ and cellobiose 17. The smaller increase in cellobiose may be due to the fact that the increased surface of the apolar version of 
cellobiose could be too large to fully stack on top of the $C-G$ base pair. Similar results were found when the apolar sugars were attached to the GGCGCC sequence (see ESIz, Table S3).

In the case of the AGCGCT sequence, both conjugates with permethylated glucose 16 and cellobiose 20 show an increase in $T_{m}\left(1^{\circ} \mathrm{C}\right.$ and $4.2^{\circ} \mathrm{C}$, respectively)

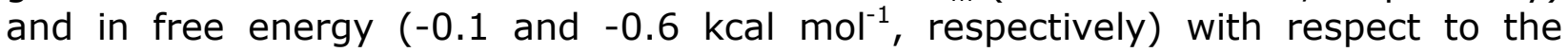
natural sequence 12. Once again, similar results were found when the apolar carbohydrates were attached to the TGCGCA sequence (see Table S3, ESI). This decrease of COC stabilization on sequences with $A-T$ or $T-A$ base pairs at the edge of the duplex with respect to the sequences with $\mathrm{C}-\mathrm{G}$ or $\mathrm{G}-\mathrm{C}$ base pairs was also observed for COCs with the natural mono- and disaccharides. This effect may be due to the larger entropy cost of reducing the fraying in the more flexible terminal $A-T$ base pair that counteracts the stabilization obtained with the stacking of the apolar sugar. ${ }^{13}$

The structures of the conjugates containing the permethylated glucose unit 15 and 16 were studied by NMR spectroscopy. Proton assignment was carried out following standard procedures. The DNA duplex structures are barely distorted by the presence of the apolar sugars as can be inferred by comparison of the DNA chemical shifts of the conjugates and the control sequences (see ESI, Fig. S2). Chemical shift changes are mostly observed in the neighboring residues of the permethylated glucose ( $\mathrm{C} 1$ in the CGCGCG sequence and $\mathrm{A} 1$ in the AGCGCT sequence), indicating that the carbohydrate is interacting mainly with the terminal residues. This capping interaction is also supported by a significant number of NOEs (see Fig. 2 and Table S2, in ESI). The number and intensities of these NOE contacts are comparable with those observed in the disaccharide conjugates studied in our previous work. ${ }^{13}$ Strong and medium NOEs are observed between several protons of the terminal base-pairs with $\mathrm{H} 3$ and $\mathrm{H} 5$ of the apolar glucose unit, suggesting that the permethylated glucose interacts with the terminal base-pair of the duplex predominantly through its a face. In the case of conjugate $\mathbf{1 6}$ some low intensity NOEs are also observed with $\mathrm{H} 4$ proton. These NOEs may arise from spin-diffusion or from minor species with different carbohydrate conformations, and were not used in the structural calculations. Interestingly, many of the DNA-permethylated glucose NOEs involve exchangeable protons of the terminal base-pair. In both conjugates, these protons exhibit narrow signals, indicating that they are protected from water exchange. As in the case of the natural disaccharide-DNA conjugates studied previously, the capping carbohydrate reduces strongly the internal dynamics of the terminal base-pairs. This effect is especially pronounced in conjugate 16, where the terminal base-pair is AT.

Restrained molecular dynamics calculations were carried out with the AMBER program. Resulting structures are shown in Fig. 3. In both conjugates $\mathbf{1 5}$ and 16, the carbohydrate and the linker adopt a similar and well-defined structure. Permethylated glucoses stack on top of the terminal base-pair, with their $\alpha$ sides oriented towards the nucleobases. Carbohydrate conformation is the usual ${ }^{4} \mathrm{C}_{1}$ chair. Permethylation increases the carbohydrate size and allows for an enhanced stacking interaction in which a single monosaccharide covers most of the terminal base-pair 
surface (Fig. 3). Although the main features of both conjugates are quite similar, minor differences are observed (see Fig. 3, top). These differences are probably due to the different adjacent nucleobase, purine in the case of conjugate $\mathbf{1 5}$ and pyrimidine for 16.

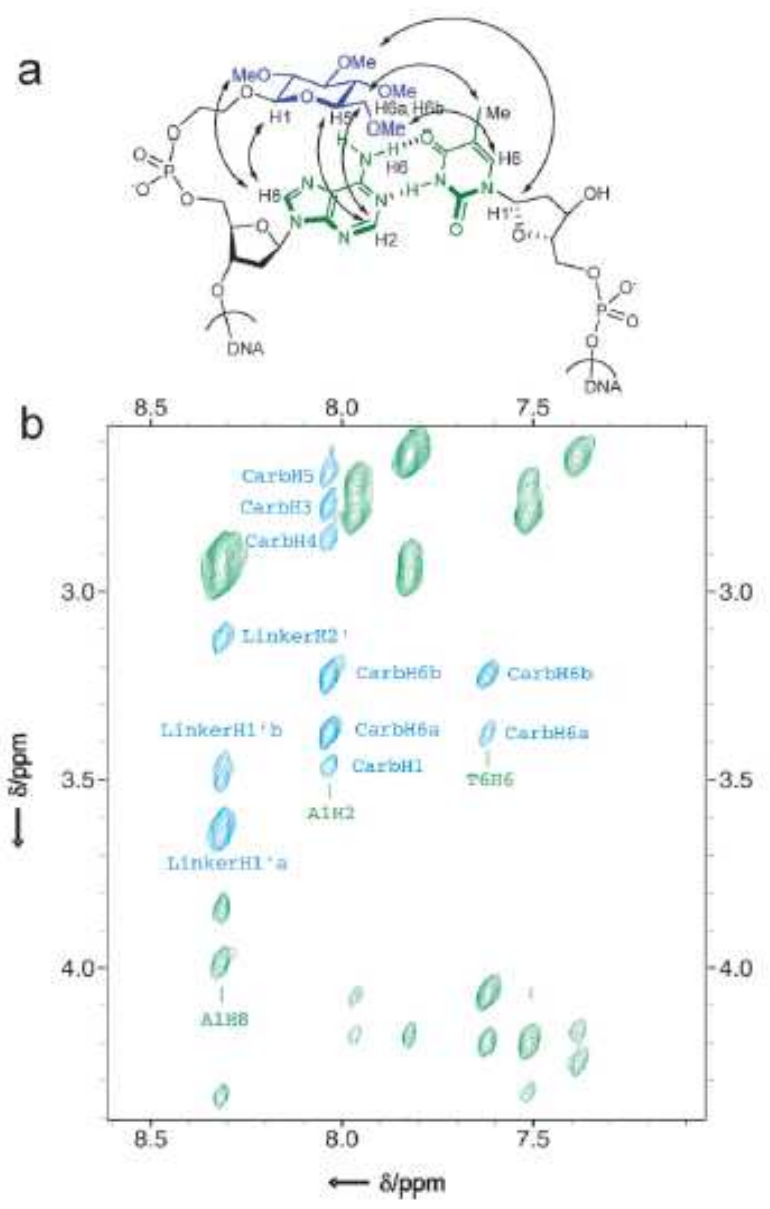

Fig. 2 (a) Schematic drawing of conjugate 16 with arrows indicating important observed NOEs; (b) selected region of NOESY spectra for conjugate 16 (carbohydrate-DNA contacts are shown in cyan).

These results are noteworthy since hydrophobic mono- and disaccharides attached to DNA show a relevant increase in stabilization of DNA duplexes especially with terminal $\mathrm{C}-\mathrm{G}$ or $\mathrm{G}-\mathrm{C}$ base pairs. In this context, the stability of DNA with apolar sugars $5^{\prime}$-caps is approaching to that found with the traditional aromatic caps. Further improvement may be obtained modulating the hydrophobicity of the carbohydrate. NMR studies confirmed that permethylated sugars stack on top of duplex DNA similarly to other aromatic moieties. Finally, our results have implications in molecular recognition and may be useful in drug design and in the assembly of supramolecular structures. 


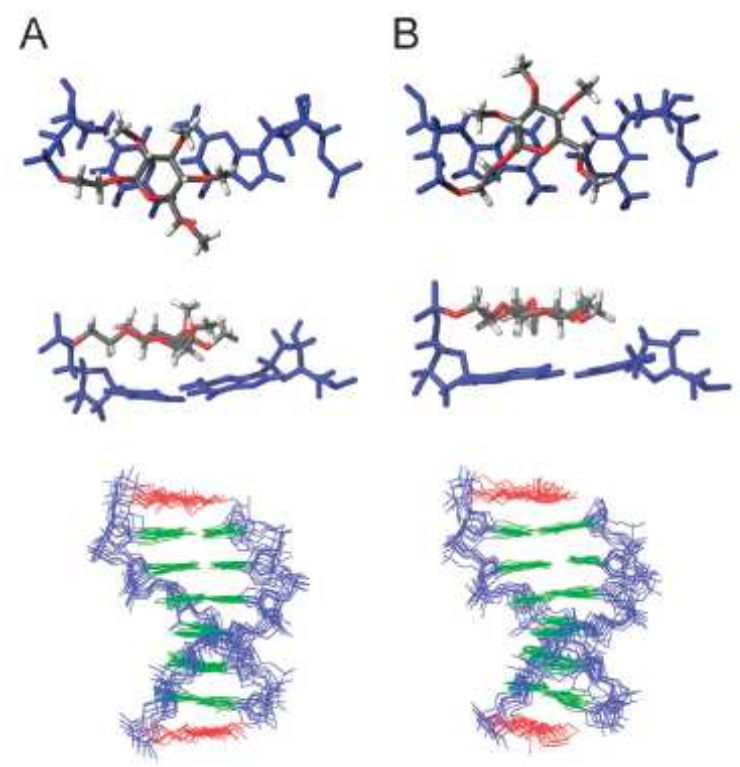

Fig. 3 Structures of conjugate 15 (A), and conjugate 16 (B). Top: details of the stacking. Bottom: superposition of ten calculated structures.

We thank the MICINN of Spain (grants CTQ2006-01123, CTQ2007-68014C02-02, CTQ2009-13705, BFU2007-63287), Generalitat de Catalunya (2009/SGR/208), and Instituto de Salud Carlos III (CIBER-BNN, CB06_01_0019) for financial support. RL thanks CSIC for a JAE contract.

\section{Notes and references}

1 S. Bommarito, N. Peyret and J. SantaLucia, Jr., Nucleic Acids Res., 2000, 28, 1929-1934.

2 K. M. Guckian, B. A. Schweitzer, R. X. F. Ren, C. J. Sheils, P. L. Paris, D. C. Tahmassebi and E. T. Kool, J. Am. Chem. Soc., 1996, 118, 8182-8183.

3 E. T. Kool, J. C. Morales and K. M. Guckian, Angew. Chem., Int. Ed., 2000, 39, 990-1009.

4 A. Zahn and C. J. Leumann, Chem.-Eur. J., 2008, 14, 1087-1094.

5 Z. Dogan, R. Paulini, J. A. Rojas Stutz, S. Narayanan and C. Richert, J. Am. Chem. Soc., 2004, 126, 4762-4763.

6 O. P. Kryatova, W. H. Connors, C. F. Bleczinski, A. A. Mokhir and C. Richert, Org. Lett., 2001, 3, 987-990.

7 J. Tuma, W. H. Connors, D. H. Stitelman and C. Richert, J. Am. Chem. Soc., 2002, 124, 4236-4246.

8 S. Egetenmeyer and C. Richert, Chem.-Eur. J., 2011, 17, 11813-11827.

9 C. F. Bleczinski and C. Richert, J. Am. Chem. Soc., 1999, 121, 10889-10894.

10 S. Hainke and O. Seitz, Angew. Chem., Int. Ed., 2009, 48, 8250-8253.

11 M. Kaufmann, M. Gisler and C. J. Leumann, Angew. Chem., Int. Ed., 2009, 48, 3810-3813. 
12 J. C. Morales, J. J. Reina, I. Díaz, A. Aviñó, P. M. Nieto and R. Eritja, Chem.-Eur. J., 2008, 14, 7828-7835.

13 R. Lucas, I. Gómez-Pinto, A. Aviñó, J. J. Reina, R. Eritja, C. González and J. C. Morales, J. Am. Chem. Soc., 2011, 133, 1909-1916. 


\section{Supplementary Information}

\section{Contents}

Table S1: NMR proton assignments of DNA control 12 and carbohydrate oligonucleotide conjugates $\mathbf{1 5}$ and $\mathbf{1 6 .}$

Table S2: Structurally relevant carbohydrate-DNA NOE

contacts for the carbohydrate oligonucleotide conjugates $\mathbf{1 5}$ and $\mathbf{1 6 .}$

Figure S1: Schematic drawings of conjugates 15 and 16 indicating

relevant carbohydrate-DNA NOEs

Figure S2: Changes in proton chemical shifts along the sequence

for the carbohydrate-oligonucleotide conjugates $\mathbf{1 5}$ and $\mathbf{1 6 .}$

Figure S3: Melting curves for DNA control 11,

and for carbohydrate-oligonucleotide conjugates 13 and 15.

Figure S4: Van't Hoff curves for

carbohydrate-oligonucleotide conjugates 15, 16, 18, 19 and 20.

Table S3: Tm's and thermodynamic data for carbohydrate oligonucleotide

conjugates 25, 26, 29 and 30 and their corresponding controls

S11

\section{Supplementary Methods}

Synthesis. General information.

S12

Preparation and characterization of compounds 2-5 and 7-10. S12

Proton and carbon NMR spectra of compounds 2-5 and 7-10. $\quad$ S17

$\begin{array}{ll}\text { Synthesis of carbohydrate-oligonucleotide conjugates } & \text { S25 }\end{array}$

$\begin{array}{ll}\text { Thermodynamic measurements } & \text { S25 }\end{array}$

HPLC chromatograms of carbohydrate oligonucleotide conjugates. $\quad$ S26

Maldi-TOF mass spectra of carbohydrate oligonucleotide conjugates. $\quad$ S27

$\begin{array}{ll}\text { NMR spectroscopy and structure calculations. } & \text { S27 }\end{array}$

$\begin{array}{ll}\text { References. } & \text { S28 }\end{array}$ 
Table S1: NMR proton assignments of carbohydrate oligonucleotide conjugates 15 and $16\left(5^{\circ} \mathrm{C}\right)$.

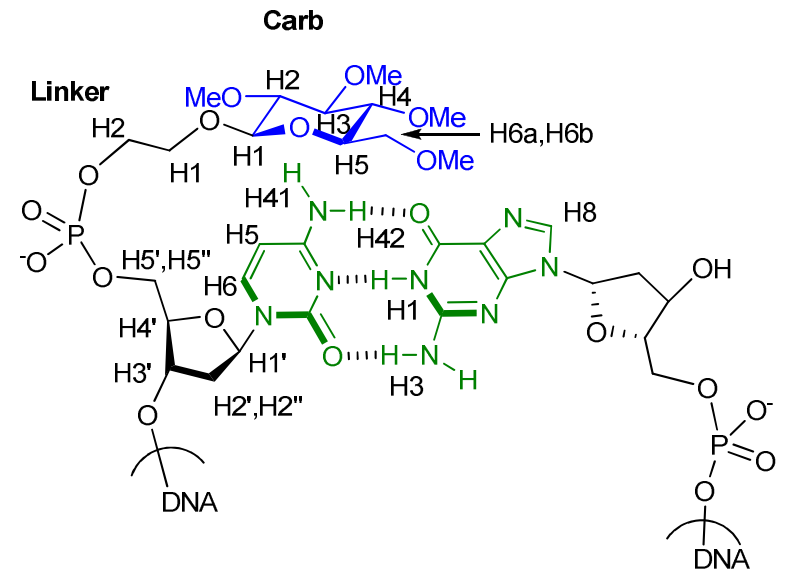

\section{Conjugate 15: Glc(Me)-C2-CGCGCG}

\begin{tabular}{cccccccccc}
\hline & H1' & H2'/H2” & H3' & H4' & H5'/H5” & H5 & H6/H8 & H1/H3 & H41/H42 \\
\hline C1 & 5.40 & $2.35 / 2.46$ & 4.85 & 4.12 & $3.97 / 3.91$ & 5.97 & 7.72 & -- & $7.35 / 8.64$ \\
G2 & 5.97 & 2.75 & & 4.38 & $4.03 / 4.13$ & -- & 8.00 & 13.19 & -- \\
C3 & 5.77 & $2.11 / 2.47$ & 4.91 & 4.24 & $4.06 / 4.14$ & 5.48 & 7.42 & -- & $6.62 / 8.49$ \\
G4 & 5.96 & $2.68 / 2.77$ & & 4.40 & $4.06 / 4.14$ & -- & 7.97 & 13.14 & -- \\
C5 & 5.75 & $1.73 / 2.23$ & 4.83 & 4.13 & $4.07 / 4.24$ & 5.53 & 7.36 & -- & $6.81 / 8.57$ \\
G6 & 6.22 & $2.75 / 2.38$ & 4.73 & 4.24 & 4.06 & -- & 8.02 & 13.30 & -- \\
\cline { 2 - 10 } & LH1a/H1b & LH2a/H2b & H1 & H2 & H3 & H4 & H5 & H6a/H6b & Met \\
\cline { 2 - 10 } glc & $3.83 / 3.93$ & $3.70 / 3.56$ & 3.97 & 2.80 & 2.98 & 2.91 & 2.98 & $3.35 / 3.23$ & 3.42 \\
\hline
\end{tabular}




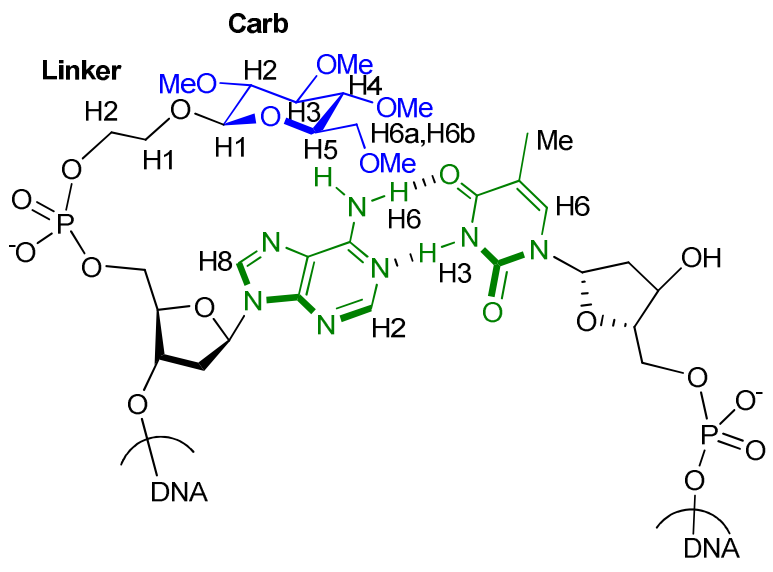

\section{Conjugate 16: Glc(Me)-C2-AGCGCT}

\begin{tabular}{cccccccccc}
\hline & $\mathrm{H}^{\prime}{ }^{\prime}$ & $\mathrm{H}^{\prime} / \mathrm{H} 2^{\prime \prime}$ & $\mathrm{H}^{\prime}$ & $\mathrm{H}^{\prime}$ & $\mathrm{H}^{\prime} / \mathrm{H} 5^{\prime \prime}$ & $\mathrm{H} 5 / \mathrm{H} 2$ & $\mathrm{H} 6 / \mathrm{H} 8$ & $\mathrm{H} 1 / \mathrm{H} 3$ & $\mathrm{H} 41 / \mathrm{H} 42$ \\
\hline $\mathrm{A} 1$ & 6.01 & $2.94 / 2.92$ & 4.85 & 4.32 & $3.84 / 3.98$ & 8.04 & 8.29 & -- & -- \\
$\mathrm{G} 2$ & 5.80 & 2.63 & & 4.41 & 4.17 & -- & 7.83 & 12.91 & -- \\
$\mathrm{C} 3$ & 5.82 & $2.09 / 2.47$ & 4.90 & 4.25 & 4.17 & 5.36 & 7.38 & -- & $6.46 / 8.30$ \\
$\mathrm{G} 4$ & 5.99 & $2.79 / 2.71$ & 4.80 & 4.42 & 4.07 & -- & 7.97 & 13.08 & -- \\
$\mathrm{C} 5$ & 6.07 & $2.08 / 2.52$ & 4.80 & 4.21 & 4.07 & 5.50 & 7.51 & -- & $6.85 / 8.42$ \\
T6 & 6.34 & $2.37 / 2.25$ & 4.64 & 4.07 & 4.20 & $1.76-\mathrm{Me}$ & 7.62 & -- & -- \\
\cline { 2 - 10 } & $\mathrm{LH} 1 \mathrm{a} / \mathrm{H} 1 \mathrm{~b}$ & $\mathrm{LH} 2 \mathrm{a} / \mathrm{H} 2 \mathrm{~b}$ & $\mathrm{H} 1$ & $\mathrm{H} 2$ & $\mathrm{H} 3$ & $\mathrm{H} 4$ & $\mathrm{H} 5$ & $\mathrm{H} 6 \mathrm{a} / \mathrm{H} 6 \mathrm{~b}$ & $\mathrm{Met}$ \\
\cline { 2 - 9 } glc & $3.62 / 3.47$ & 3.12 & 3.45 & 2.62 & 2.76 & 2.85 & 2.69 & $3.22 / 3.37$ & 3.22 \\
\hline
\end{tabular}

\section{Control 12: AGCGCT}

\begin{tabular}{lccccccccc}
\hline & $\mathrm{H}^{\prime}$ & $\mathrm{H}^{\prime} / \mathrm{H} 2^{\prime}$ & $\mathrm{H}^{\prime}$ & $\mathrm{H}^{\prime}$ & $\mathrm{H}^{\prime} / \mathrm{H}^{\prime}{ }^{\prime}$ & $\mathrm{H} 5 / \mathrm{H} 2$ & $\mathrm{H} 6 / \mathrm{H} 8$ & $\mathrm{H} 1 / \mathrm{H} 3$ & $\mathrm{H} 41 / \mathrm{H} 42$ \\
\hline $\mathrm{A} 1$ & 5.98 & $2.54 / 2.70$ & 4.86 & 4.23 & 3.71 & & 8.07 & & \\
$\mathrm{G} 2$ & 5.83 & 2.70 & & 4.41 & $4.13 / 4.24$ & & 7.91 & 12.97 & \\
$\mathrm{C} 3$ & 5.80 & $2.08 / 2.45$ & 4.88 & 4.24 & $4.08 / 4.17$ & 5.38 & 7.38 & & $6.50 / 8.32$ \\
$\mathrm{G} 4$ & 5.97 & $2.78 / 2.69$ & & 4.41 & $4.08 / 4.19$ & & 7.96 & 13.07 & \\
$\mathrm{C} 5$ & 6.13 & $2.26 / 2.52$ & 4.80 & 4.26 & $4.08 / 4.20$ & 5.52 & 7.52 & & $6.82 / 8.41$ \\
T6 & 6.30 & 2.31 & 4.20 & 4.09 & 4.23 & $1.77-\mathrm{Me}$ & 7.61 & & \\
\hline
\end{tabular}


Table S2: Structurally relevant carbohydrate-DNA NOE contacts for the carbohydrate oligonucleotide conjugates glc(Me)-C2-CGCGCG 15 and glc(Me)-C2-AGCGCT 16. (Strong NOE: s, medium NOE: m, weak NOE: w, very weak NOE: vw).

\begin{tabular}{ll}
\hline \multicolumn{1}{c}{15} \\
\multicolumn{1}{c}{ Carb } & \multicolumn{1}{c}{ Linker } \\
\hline C1H5-H3/GlcH5: w & C1H5-LH2': s \\
C1H4'-GlcMe: s & C1H5-LH1': m \\
C1H4'-GlcH3/H5: w & C1H6-LH2': m \\
C1H1'-GlcH3/H5: vw & C1H6-LH1': m \\
C1H41-GlcH3: w & C1H4'-LH2': vw \\
C1H42-GlcH3: w & \\
C1H42-GlcMe: w & \\
\hline *G6H8-GlcH3/H5: m & \\
G6H1'-GlcMe: s & \\
*G6H1'-GlcH3/H5: m/s & \\
G6H3-GlcH3: s & \\
G6H3-GlcMe: vw & \\
\hline
\end{tabular}

A1H4'-GlcMe: w

T6Me-GlcH6a: w

T6Me-GlcH6b: m

T6H6-GlcMe: $\mathrm{m}$

T6H6-GlcH6a: w

T6H6-GlcH6b: w

T6H1'-GlcMe: w

T6H1'-GlcH6a: w

T6H1'-GlcH6b: m

T6H2'/H2' '-GlcH6a: m

T6H2'/H2' '-GlcH6b: m
16

\begin{tabular}{ll}
\hline \multicolumn{1}{c}{ Carb } & \multicolumn{1}{c}{ Linker } \\
\hline A1H2-GlcMe: m & A1H8-LH1'a: s \\
A1H2-GlcH6a: m & A1H8-LH1'b: s \\
A1H2-GlcH6b: m & A1H8-LH2': m \\
A1H2-GlcH1: w & A1H5'/H5''- LH2': w \\
A1H2-GlcH3: m & \\
*A1H2-GlcH4: w & \\
A1H2-GlcH5: m & \\
A1H8-GlcMe: w & \\
A1H8-GlcH1: m & \\
*A1H8-GlcH2: w & \\
\hline
\end{tabular}


*Not used in structure calculations 
Figure S1: Schematic drawings of conjugates 15 and 16 indicating relevant carbohydrate-DNA NOEs.
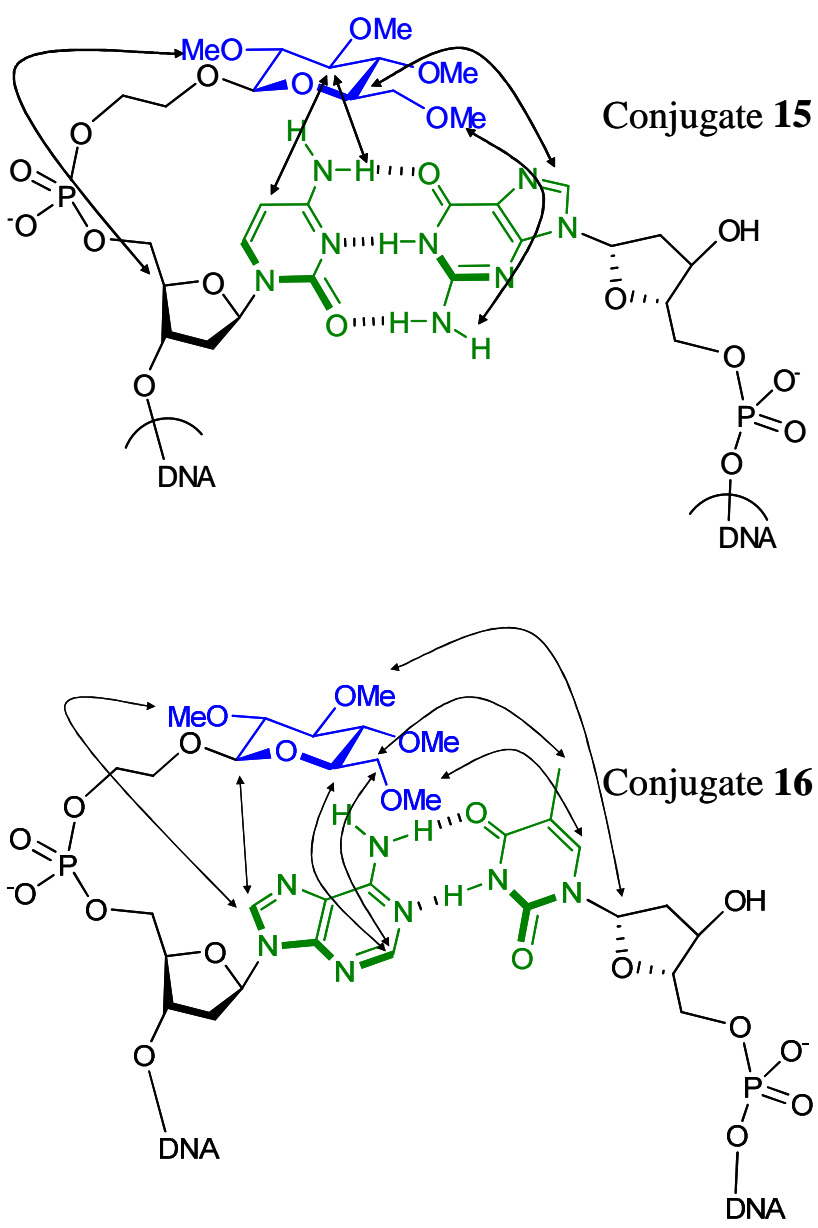
Figure S2: Changes in proton chemical shifts along the sequence for the carbohydrateoligonucleotide conjugates $\mathbf{1 5}$ and $\mathbf{1 6}$ with respect to DNA controls $\mathbf{1 1}$ and 12, respectively.

Conjugate 15: glc(Me)-C2-CGCGCG.

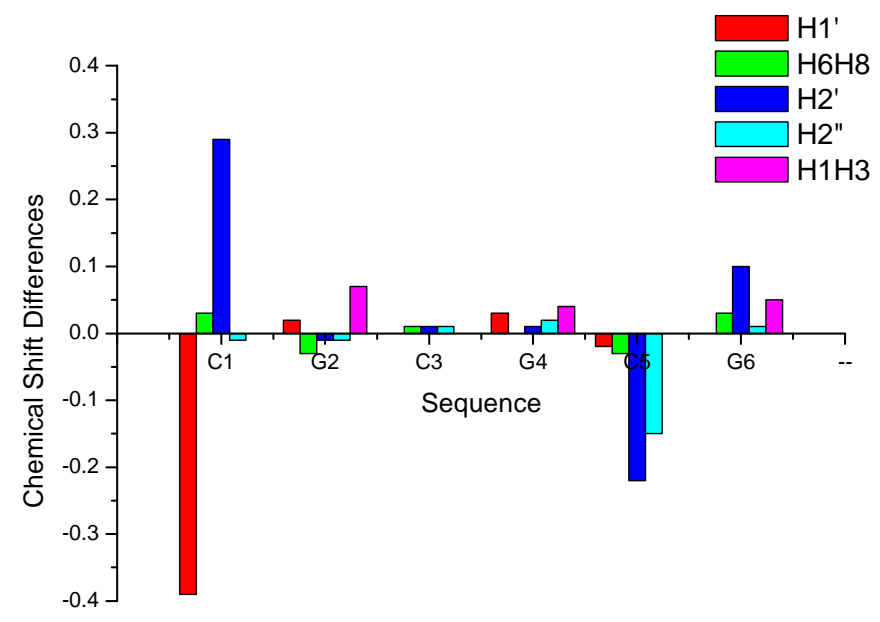

Conjugate 16: glc(Me)-C2-AGCGCT.

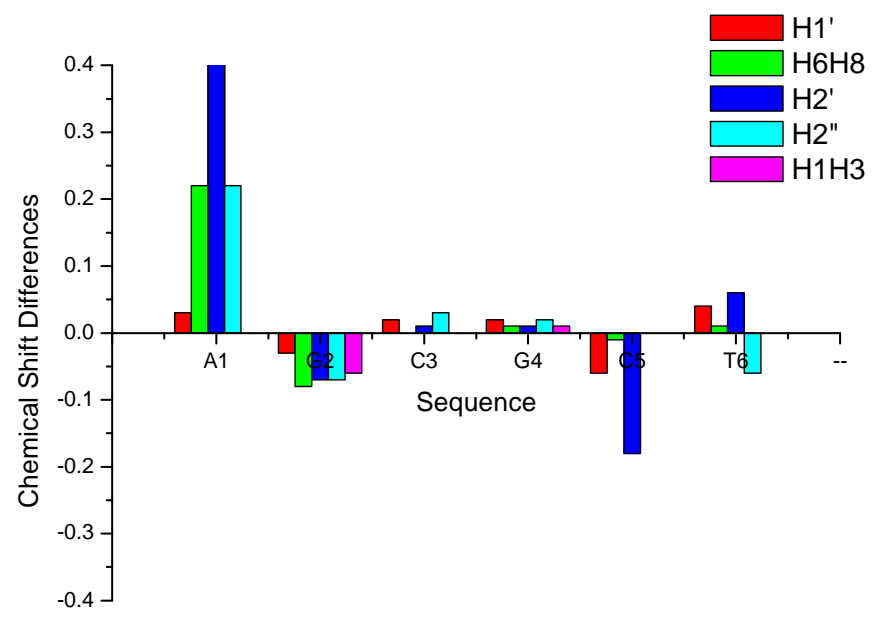

Figure S3: Melting curves for: Glc(Me)-C2- CGCGCG 15 and Glc(Me)-C2- AGCGCT 16. 

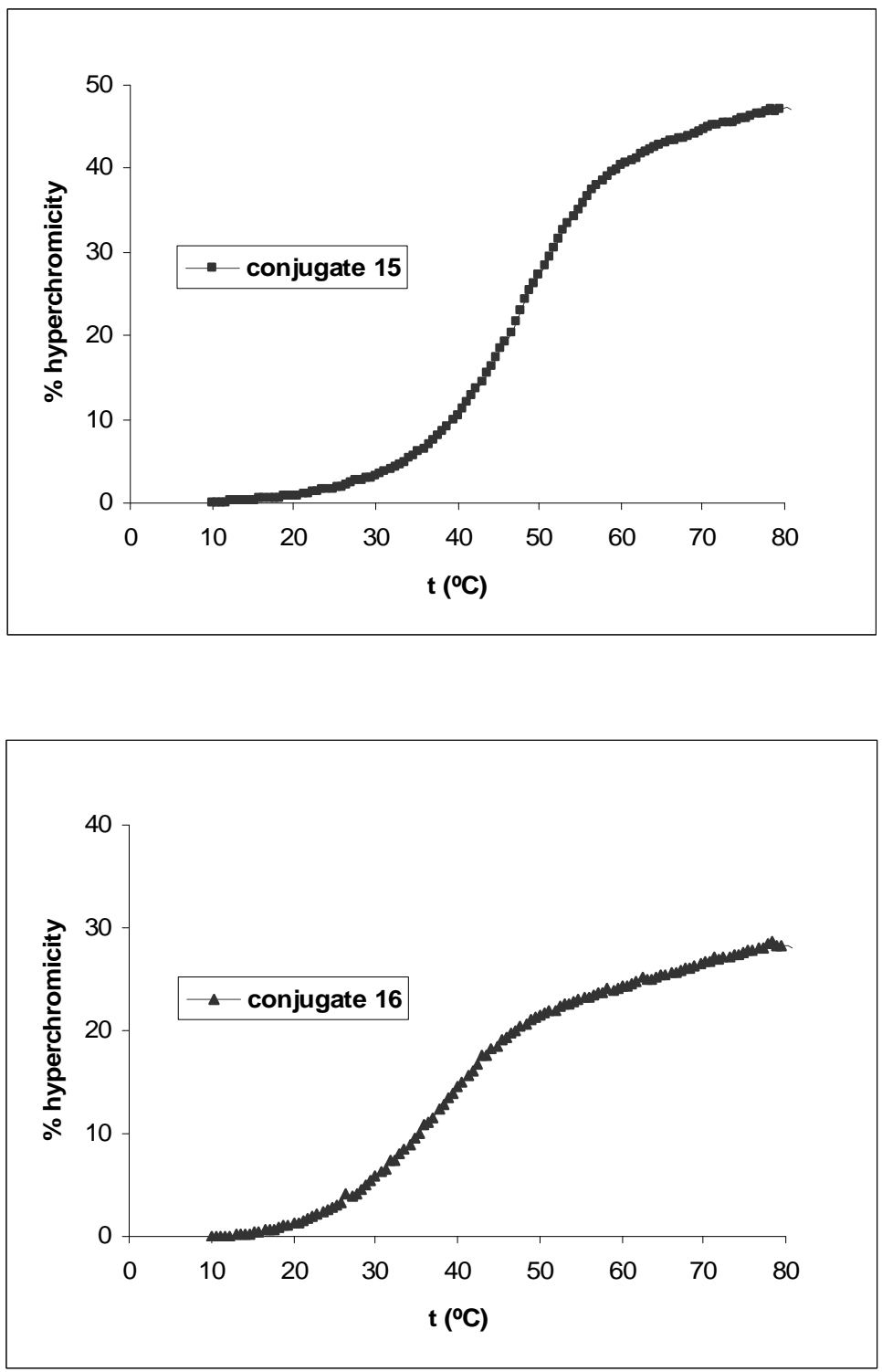
Figure S4: Van't Hoff curves for DNA controls 11 and 12 and for DNA carbohydrateoligonucleotide conjugates 13, 14, 15, 16, 17, 18, 19, 25, 26, 29 and 30.

DNA control 11: CGCGCG $(\bullet)$, conjugate 13: glc-C2-CGCGCG $(\square)$ and conjugate 15: $\operatorname{glc}(\mathrm{Me})-\mathrm{C} 2-\mathrm{CGCGCG}(\boldsymbol{\Delta})$.

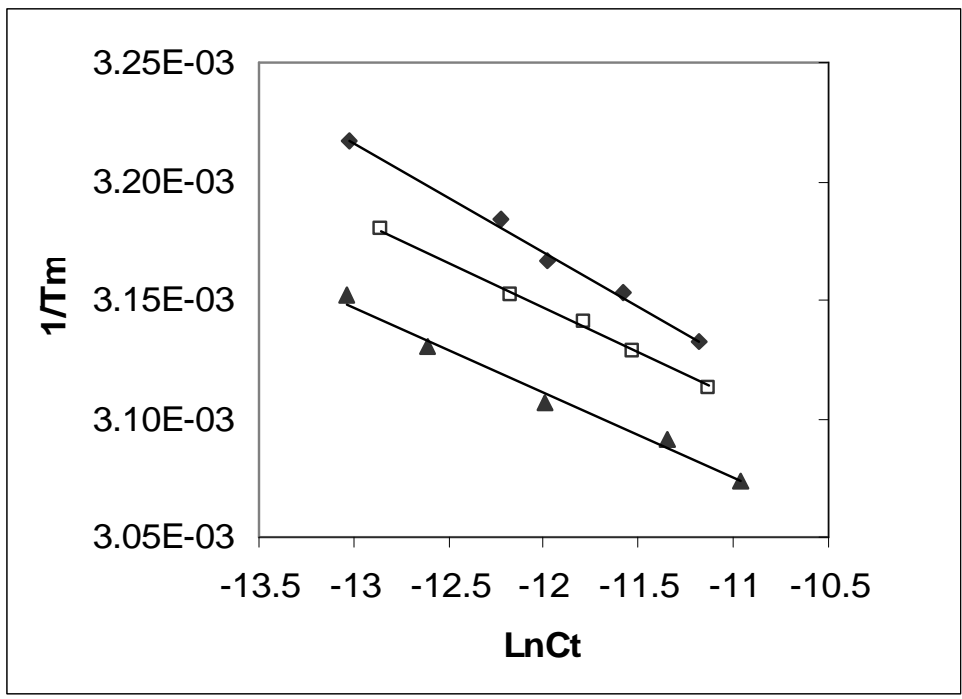

DNA control 12: AGCGCT $(\diamond)$, conjugate 14: glc-C2-AGCGCT ( $\square)$ and conjugate 16: $\operatorname{glc}(\mathrm{Me})-\mathrm{C} 2-\mathrm{AGCGCT}(\triangle)$.

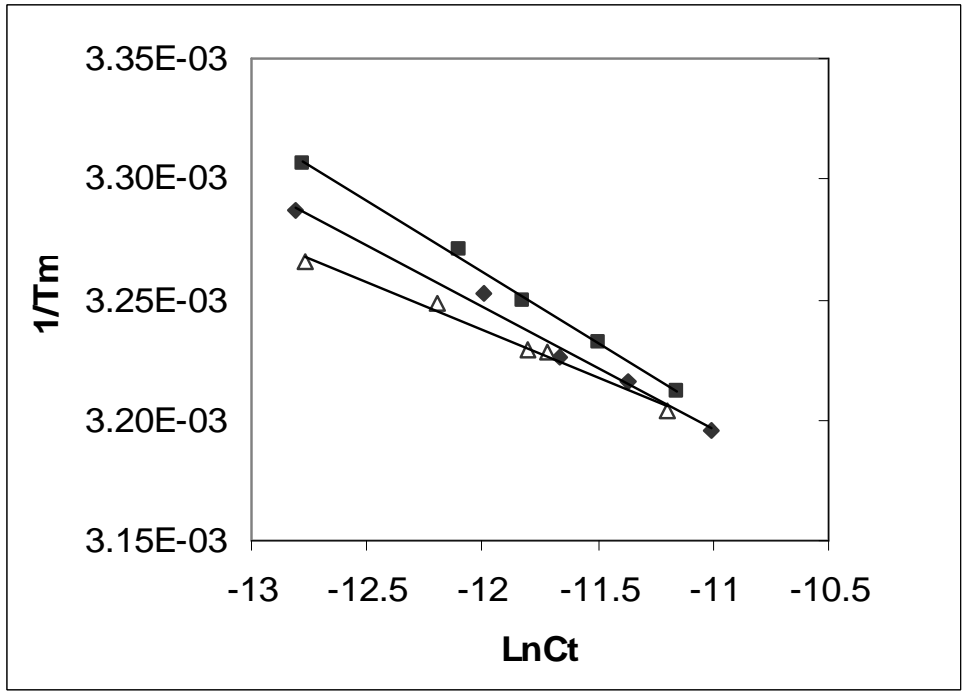

DNA control 11: CGCGCG $(\bullet)$, conjugate 17: cellob-C2-CGCGCG $(\bullet)$ and 19: cellob(Me)C2-CGCGCG (O). 


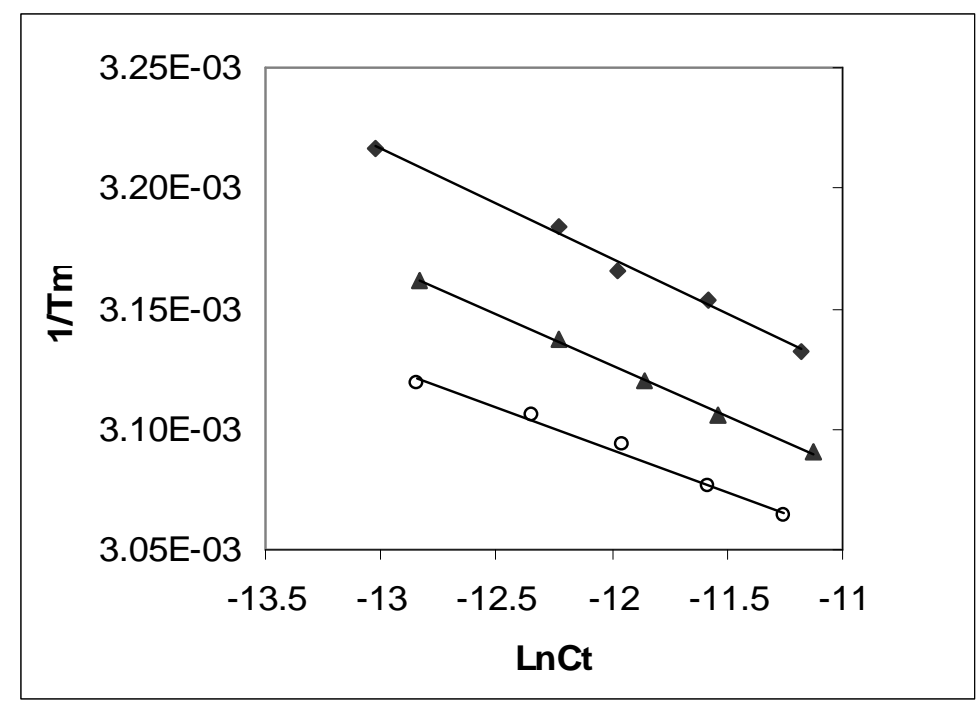

DNA control 12: AGCGCT $(\bullet)$, conjugate 18: cellob-C2-AGCGCT $(\bullet)$ and conjugate 20: cellob(Me)-C2-AGCGCT (ם).

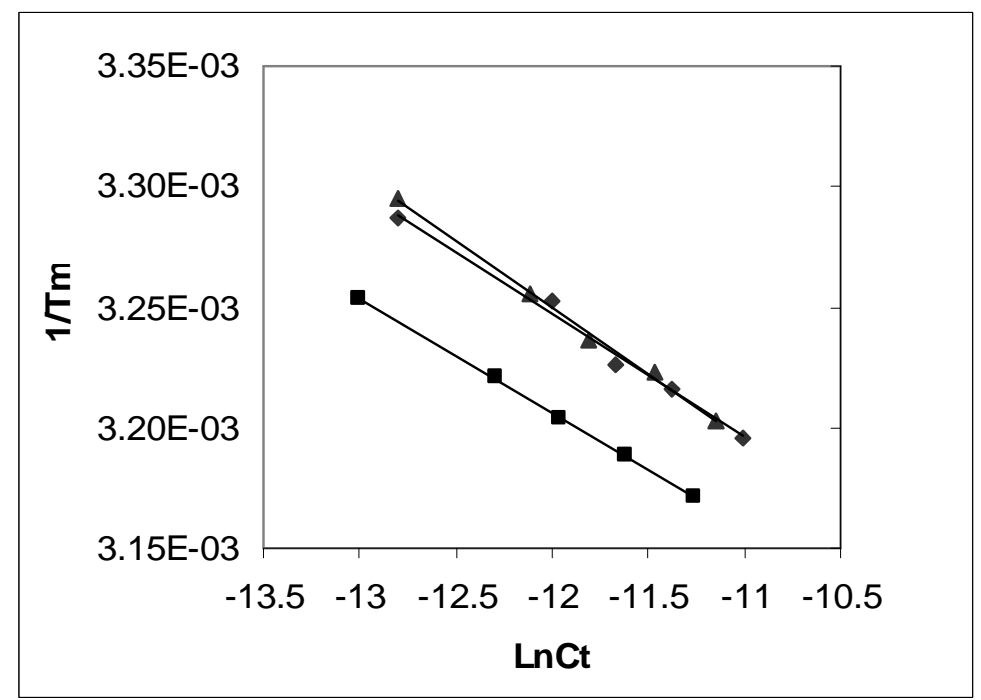


Conjugate 25: glc(Me)-C2-GGCGCC ( ) and conjugate 29: glc(Me)-C2-GGCGCC (घ).

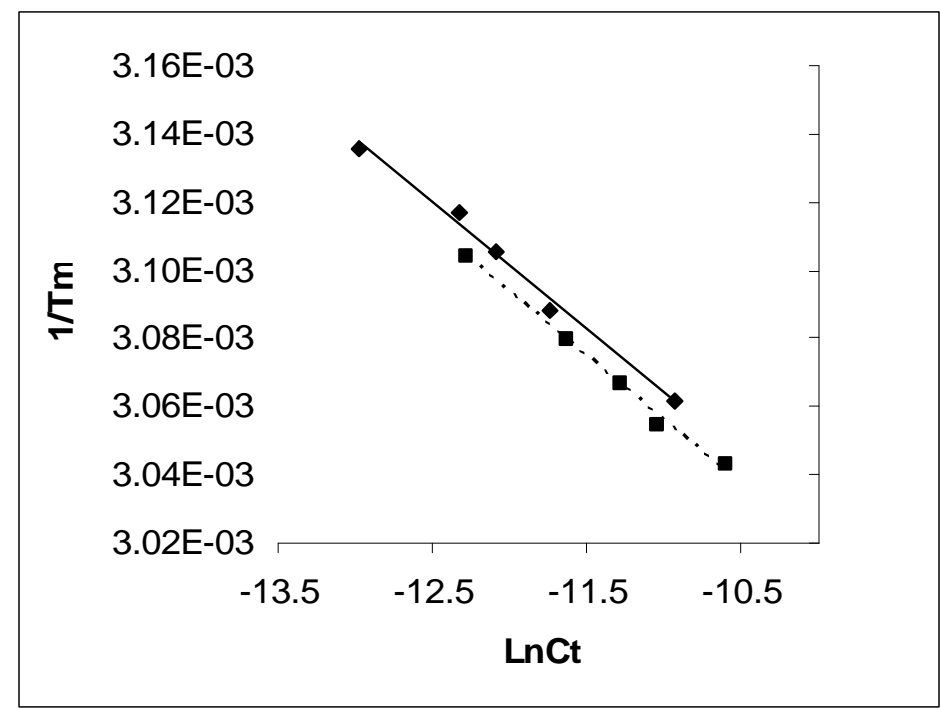

Conjugate 26: glc(Me)-C2-TGCGCA $(\bullet)$ and conjugate 30: cellob(Me)C2-TGCGCA (O).

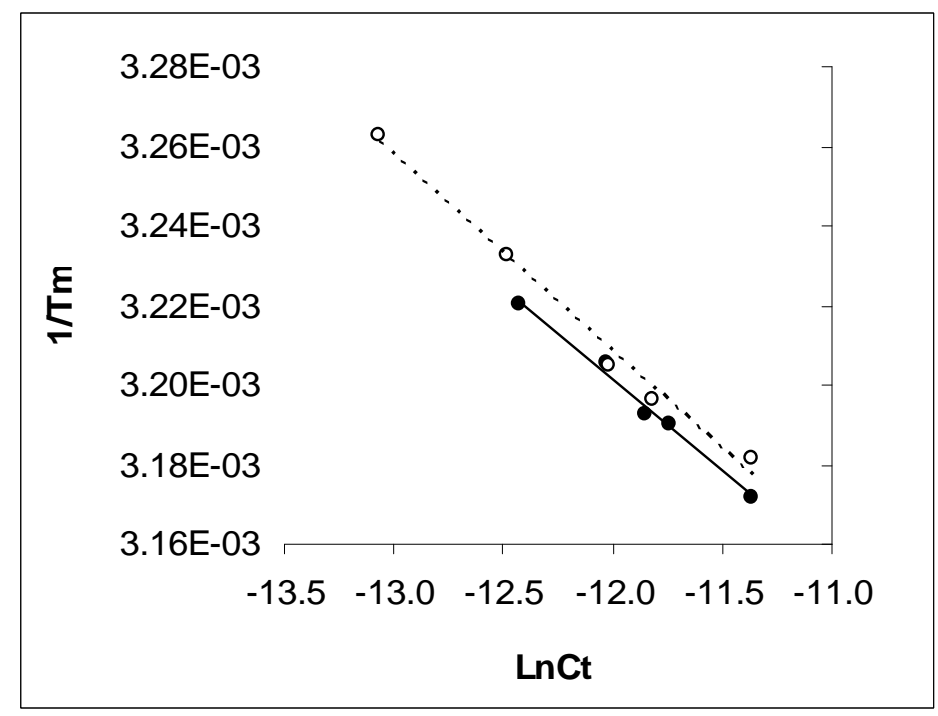


Table S3: Tm's and thermodynamic data for COCs $\mathbf{2 3}$ to $\mathbf{3 0}$ and their corresponding controls 21 and 22.

\begin{tabular}{|c|c|c|c|c|c|}
\hline $\begin{array}{l}\text { X-DNA sequence } \\
a, b, c, d\end{array}$ & $\begin{array}{l}\mathrm{Tm} \\
\left({ }^{\circ} \mathrm{C}\right) e\end{array}$ & $-\Delta H^{\circ}$ & $-\Delta S^{\circ}$ & $-\Delta G_{37}$ & $\Delta \Delta G_{37}^{\circ}$ \\
\hline \multicolumn{6}{|l|}{$\mathrm{X}=$ none $f$} \\
\hline GGCGCC $\mathbf{2 1}$ & 37.6 & 45.6 & 122 & 7.8 & - \\
\hline TGCGCA $\quad 22$ & 34.8 & 37.8 & 99 & 7.2 & - \\
\hline \multicolumn{6}{|l|}{$\mathrm{X}=$ glucose $-\mathrm{C} 2 f$} \\
\hline GGCGCC & 42.2 & 46.7 & 124 & 8.3 & -0.5 \\
\hline TGCGCA $\mathbf{2 4}$ & 34.2 & 47.8 & 131 & 7.2 & 0.0 \\
\hline \multicolumn{6}{|l|}{$\mathrm{X}=\operatorname{glc}(\mathrm{Me})-\mathrm{C} 2$} \\
\hline GGCGCC $\quad \mathbf{2 5}$ & 48.7 & 53.5 & 142 & -9.5 & -1.7 \\
\hline TGCGCA $\mathbf{2 6}$ & 37.4 & 44.7 & 119 & -7.7 & -0.5 \\
\hline \multicolumn{6}{|l|}{$\mathrm{X}=$ cellobiose $-\mathrm{C} 2 f$} \\
\hline $\begin{array}{ll}\text { GGCGCC } & \mathbf{2 7}\end{array}$ & 44.2 & 51.9 & 139 & 8.7 & -0.9 \\
\hline TGCGCA $\mathbf{2 8}$ & 35.2 & 43.9 & 118 & 7.2 & 0.0 \\
\hline \multicolumn{6}{|l|}{$\mathrm{X}=$ cellob $(\mathrm{Me})-\mathrm{C} 2$} \\
\hline GGCGCC $\quad \mathbf{2 9}$ & 50.7 & 54.0 & 143 & -9.6 & -1.8 \\
\hline TGCGCA $\quad 30$ & 37.6 & 43.1 & 114 & -7.6 & -0.4 \\
\hline \multicolumn{6}{|c|}{ 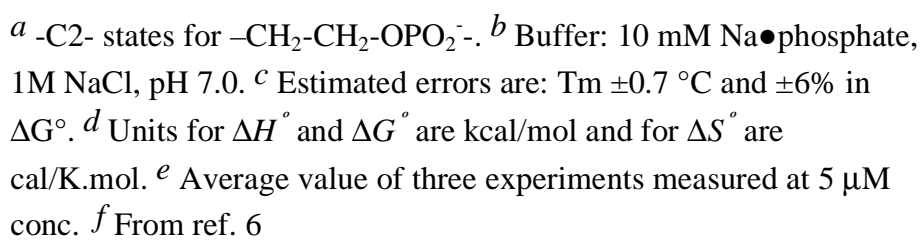 } \\
\hline
\end{tabular}




\section{Supplementary Methods}

\section{Synthesis. General information.}

All chemicals were obtained from chemical suppliers and used without further purification, unless otherwise noted. All reactions were monitored by TLC on precoated Silica-Gel 60 plates F254, and detected by heating with Mostain (500 ml of 10\% $\mathrm{H}_{2} \mathrm{SO}_{4}, 25 \mathrm{~g}$ of $\left.\left(\mathrm{NH}_{4}\right)_{6} \mathrm{Mo}_{7} \mathrm{O}_{24} \bullet 4 \mathrm{H}_{2} \mathrm{O}, 1 \mathrm{~g} \mathrm{Ce}\left(\mathrm{SO}_{4}\right)_{2} \bullet 4 \mathrm{H}_{2} \mathrm{O}\right)$. Products were purified by flash chromatography with silica gel60 (200-400 mesh).

NMR spectra were recorded on either a Bruker AVANCE 300 or ARX 400 or Bruker Advance DRX $500 \mathrm{MHz}$ [300 or $400 \mathrm{MHz}(1 \mathrm{H}), 75$ or $100\left({ }^{13} \mathrm{C}\right)$, at room temperature for solutions in $\mathrm{CDCl}_{3}, \mathrm{D}_{2} \mathrm{O}$ or $\mathrm{CD}_{3} \mathrm{OD}$ ]. Chemical shifts are referred to the solvent signal and are expressed in ppm. 2D NMR experiments (COSY, TOCSY, ROESY, and HMQC) were carried out when necessary to assign the corresponding signals of the new compounds. High resolution FAB (+) mass spectral analyses was obtained on a Micromass AutoSpec-Q spectrometer.

\section{Preparation and characterization of compounds 2-5 and 7-10.}

\section{2-Benzyloxyethyl- $\beta$-D-glucopyranoside (2)}

To a solution of the tetraacetyl glucopyranosyl trichloroacetimidate $\mathbf{1}^{\mathbf{1}}$ (600 $\mathrm{mg}, 1.21$ mmol) in anhydrous $\mathrm{CH}_{2} \mathrm{Cl}_{2}(10 \mathrm{~mL})$ and 2-benzyloxyethanol $(520 \mu \mathrm{L}, 3.65 \mathrm{mmol})$, $\mathrm{BF}_{3} . \mathrm{OEt}_{2}(20 \mu \mathrm{l}, 0.24 \mathrm{mmol})$ was then added. After stirring at room temperature for $1 \mathrm{~h}$ under argon atmosphere, $\mathrm{NEt}_{3}(0.2 \mathrm{ml})$ was then added. Solvents were then removed and the crude was purified by silica gel column chromathography using as eluent (HexAcOEt, 2:1-2:3) to give the glycosyl derivative as a syrup. This product (560 mg, 1.16 mmol) was dissolved in dry $\mathrm{MeOH}(10 \mathrm{~mL})$ and $\mathrm{Na}_{2} \mathrm{CO}_{3}(40 \mathrm{mg}, 0.35 \mathrm{mmol})$ was then added. The reaction mixture was stirred for $1 \mathrm{~h}$ and IR-120 was then added to neutralize. Solvent was then removed and the crude was purified by silica gel column chromathography using as eluent (AcOEt:MeOH, 1:0-1:1) to give 2 (290 mg, 80\%, 2 steps) as a syrup. $[\alpha]_{\mathrm{D}}{ }^{20}-16.2$ (c 1 in $\left.\mathrm{MeOH}\right) ;{ }^{1} \mathrm{H} \mathrm{NMR}\left(\mathrm{CD}_{3} \mathrm{OD}, 300 \mathrm{MHz}\right) \delta(\mathrm{ppm})$ 7.39-7.29 (m, 5 H, Ph), 4.58 (d, 1H, J = 7.7 Hz, H-1), 3.89-3.85 (m, 1H, ), 3.80-3.65 $\left.(\mathrm{m}, 4 \mathrm{H}),, 3.38-3.20(\mathrm{~m}, 4 \mathrm{H}),, \mathrm{OCH}_{2} \mathrm{CH}_{2} \mathrm{O}-\right) .{ }^{13} \mathrm{C} \mathrm{NMR}\left(\mathrm{CD}_{3} \mathrm{OD}, 75 \mathrm{MHz}\right) \delta(\mathrm{ppm})$ 
141.9 (Cq arom), 131.9, 131.7, 131.4 (Carom), $106.9\left(\mathrm{C}_{1}\right)$, 80.5, 80.4, 77.6, 76.8, 74.1, 73.2, 72.1, 65.3. HRMS $\left(\mathrm{ES}^{+}\right)$Calcd. for $\mathrm{C}_{15} \mathrm{H}_{22} \mathrm{NaO}_{7}(\mathrm{M}+\mathrm{Na})$ : 337.1263, found; 337.1264 .

\section{2-Benzyloxyethyl 2,3,4,6-tetra- $O$-methyl- $\beta$-D-glucopyranoside (3)}

To a solution of compound $2(600 \mathrm{mg}, 1.91 \mathrm{mmol})$ in anhydrous DMF $(10 \mathrm{~mL})$ at $0^{\circ} \mathrm{C}$, $\mathrm{NaH}$ (275 mg, $11.46 \mathrm{mmol}$ ) was added. The reaction mixture was stirred for $10 \mathrm{~min}$ and MeI $(952 \mu \mathrm{L}, 15.28 \mathrm{mmol})$ was added. After $18 \mathrm{~h}, 2$-propanol was then added dropwise and finally $\mathrm{NH}_{4} \mathrm{Cl}$ sat $(50 \mathrm{~mL})$ was also added. The organic phase was extracted with ethyl acetate $(2 \times 100 \mathrm{~mL})$ and washed with sodium bisulfate solution $(50 \mathrm{~mL})$ and brine $(50 \mathrm{~mL})$. Solvents were then removed and the crude was purified by silica gel column chromathography using as eluent (Hex-AcOEt, 2:1-1:2) to give 3 (620 mg, 88\%) as a syrup. $[\alpha]_{\mathrm{D}}{ }^{20}-21.5$ (c 1 in $\left.\mathrm{CHCl}_{3}\right) ;{ }^{1} \mathrm{H}$ NMR $\left(\mathrm{CDCl}_{3}, 300 \mathrm{MHz}\right): \delta(\mathrm{ppm})$ 7.26-7.18 (m, $5 \mathrm{H}, \mathrm{Ph}), 4.48\left(\mathrm{~s}, 2 \mathrm{H}, \mathrm{CH}_{2} \mathrm{Ph}\right), 4.21\left(\mathrm{~d}, 1 \mathrm{H}, J=7.8 \mathrm{~Hz}, \mathrm{H}_{1}\right), 3.96-3.93(\mathrm{~m}, 1 \mathrm{H}$, $\mathrm{OCH}_{2} \mathrm{CH}_{2} \mathrm{OBn}$ ), 3.68-3.57 (m, 3H, $\left.\mathrm{OCH}_{2} \mathrm{CH}_{2} \mathrm{OBn}\right), 3.54$ (s, $\left.3 \mathrm{H}, \mathrm{CH}_{3} \mathrm{O}\right), 3.52-3.47$ (m, $\left.5 \mathrm{H}, \mathrm{H}_{6}, \mathrm{H}_{6}, \mathrm{CH}_{3} \mathrm{O}\right), 3.30$ (s, $3 \mathrm{H}, \mathrm{CH}_{3} \mathrm{O}$ ), 3.19-3.16 (m, $\left.1 \mathrm{H}, \mathrm{H}_{5}\right), 3.08-3.05$ (m, $2 \mathrm{H}$, $\left.\mathrm{H}_{3}, \mathrm{H}_{4}\right), 2.97-2.94\left(\mathrm{~m}, 1 \mathrm{H}, \mathrm{H}_{2}\right) .{ }^{13} \mathrm{C} \mathrm{NMR}\left(\mathrm{CD}_{3} \mathrm{OD}, 75 \mathrm{MHz}\right) \delta(\mathrm{ppm}) 138.2$ (Cq arom), 128.4, 127.6, 127.5 (Carom), $103.5\left(\mathrm{C}_{1}\right), 86.3\left(\mathrm{C}_{3}\right), 83.6\left(\mathrm{C}_{2}\right), 79.3\left(\mathrm{C}_{4}\right), 74.5\left(\mathrm{C}_{5}\right), 73.1$ $\left(\mathrm{CH}_{2} \mathrm{Ph}\right), 71.3\left(\mathrm{C}_{6}\right), 69.2,68.9\left(\mathrm{OCH}_{2}\right), 60.7,60.4,60.3,59.3\left(\mathrm{CH}_{3} \mathrm{O}\right) . \mathrm{HRMS}\left(\mathrm{ES}^{+}\right)$ Calcd. for $\mathrm{C}_{19} \mathrm{H}_{30} \mathrm{NaO}_{7}(\mathrm{M}+\mathrm{Na}): 393.1989$, found; 393.1880 .

\section{2-Hydroxyethyl 2,3,4,6-tetra- $O$-methyl- $\beta$-D-glucopyranoside (4)}

A solution of compound $3(500 \mathrm{mg}, 1.349 \mathrm{mmol})$ in ethyl acetate-MeOH $(1: 1,5 \mathrm{~mL})$ and $\mathrm{Pd}(\mathrm{OH})_{2}$ in catalytic amount was stirred under an atmosphere of hydrogen for $18 \mathrm{~h}$. The mixture was filtered off over celite and solvents were removed. The crude was

purified by silica gel column chromathography using as eluent (Hex-AcOEt, 1:3) to give $4(320 \mathrm{mg}, 82 \%)$ as a syrup. $[\alpha]_{\mathrm{D}}{ }^{20}-2.5$ (c 1 in $\left.\mathrm{CHCl}_{3}\right) ;{ }^{1} \mathrm{H} \mathrm{NMR}\left(\mathrm{CDCl}_{3}, 300\right.$ $\mathrm{MHz}): \delta(\mathrm{ppm}) 4.20\left(\mathrm{~d}, 1 \mathrm{H}, J=7.8 \mathrm{~Hz}, \mathrm{H}_{1}\right), 3.82-3.61\left(\mathrm{~m}, 4 \mathrm{H}, \mathrm{OCH}_{2} \mathrm{CH}_{2} \mathrm{OBn}\right), 3.57$ (s, $\left.4 \mathrm{H}, \mathrm{H}_{6}, \mathrm{CH}_{3} \mathrm{O}\right), 3.51\left(\mathrm{~s}, 3 \mathrm{H}, \mathrm{CH}_{3} \mathrm{O}\right), 3.49-3.43\left(\mathrm{~m}, 4 \mathrm{H}, \mathrm{H}_{6}, \mathrm{CH}_{3} \mathrm{O}\right), 3.30(\mathrm{~s}, 3 \mathrm{H}$, $\left.\mathrm{CH}_{3} \mathrm{O}\right), 3.29-3.24\left(\mathrm{~m}, 1 \mathrm{H}, \mathrm{H}_{5}\right), 3.13-3.02\left(2 \mathrm{t}, 2 \mathrm{H}, \mathrm{J}=9.0 \mathrm{~Hz}, \mathrm{H}_{3}, \mathrm{H}_{4}\right), 2.94(\mathrm{t}, 1 \mathrm{H}, \mathrm{J}=$ $\left.9.0 \mathrm{~Hz}, \mathrm{H}_{2}\right) .{ }^{13} \mathrm{C} \mathrm{NMR}\left(\mathrm{CDCl}_{3}, 75 \mathrm{MHz}\right) \delta(\mathrm{ppm}) ; 103.8\left(\mathrm{C}_{1}\right), 86.4\left(\mathrm{C}_{3}\right), 83.6\left(\mathrm{C}_{2}\right), 79.5$ 
$\left(\mathrm{C}_{4}\right)$, $74.1\left(\mathrm{C}_{5}\right), 73.4,71.4,62.3,60.7,60.4,60.3,59.2\left(\mathrm{CH}_{3} \mathrm{O}\right) . \mathrm{HRMS}\left(\mathrm{ES}^{+}\right)$Calcd. for $\mathrm{C}_{12} \mathrm{H}_{24} \mathrm{NaO}_{7}(\mathrm{M}+\mathrm{Na}): 303.1420$, found; 303.1431 .

2-(2,3,4,6-Tetra- $O$-methyl- $\beta$-D-glucopyranosyloxy)ethyl (2-cyanoethyl) $\quad(N, N$ diisopropyl) phosphoramidite (5)

DIEA (0.695 mL, $4.0 \mathrm{mmol})$ and 2-cyanoethyl-N, N'-diisopropylaminochlorophosphoramidite (334 $\mu \mathrm{L}, 1.5 \mathrm{mmoL})$ were added to a solution of compound 4 (280 mg, $1.0 \mathrm{mmol})$ in anhydrous $\mathrm{CH}_{2} \mathrm{Cl}_{2}(5 \mathrm{~mL})$ at room temperature under an argon atmosphere. After $1.0 \mathrm{~h}$ no starting material was observed. Solvent was then removed and the crude was purified by silica gel column chromatography by using Hex/EtOAc (1:1 with $5 \%$ of $\left.\mathrm{NEt}_{3}\right)$ to give compound $5(450 \mathrm{mg}, 93 \%)$ as a syrup. ${ }^{1} \mathrm{H} \mathrm{NMR}\left(\mathrm{CDCl}_{3}\right.$, $300 \mathrm{MHz}$ ) (mix of isomers) $\delta(\mathrm{ppm}) 4.19\left(\mathrm{~d}, 1 \mathrm{H}, J=7.8 \mathrm{~Hz}, \mathrm{H}_{1}\right), 3.93-3.44(\mathrm{~m}, 6 \mathrm{H}$, $\mathrm{OCH}_{2} \mathrm{CH}_{2} \mathrm{O}, \mathrm{OC}_{2}{ }_{2} \mathrm{CH}_{2} \mathrm{CN}$ ), 3.61-3.44 (m, $\left.12 \mathrm{H}, 3 \mathrm{x} \mathrm{CH}_{3} \mathrm{O}, \mathrm{H}_{6}, \mathrm{H}_{6}, 2 \mathrm{xCH}_{\text {isopropyl }}\right), 3.31$ (s, $\left.3 \mathrm{H}, \mathrm{CH}_{3} \mathrm{O}\right), 3.18-3.16\left(\mathrm{~m}, 1 \mathrm{H}, \mathrm{H}_{5}\right), 3.08-3.05\left(\mathrm{~m}, 2 \mathrm{H}, \mathrm{H}_{4}, \mathrm{H}_{3}\right), 2.93-2.90(\mathrm{~m}, 1 \mathrm{H}$, $\left.\mathrm{H}_{2}\right), 2.59-2.55\left(\mathrm{~m}, 2 \mathrm{H},-\mathrm{OCH}_{2} \underline{\mathrm{C}}_{2} \mathrm{CN}\right), 1.11\left(\mathrm{~d}, 12 \mathrm{H}, \mathrm{J}=6.5 \mathrm{~Hz}, 4 \mathrm{CH}_{3 \text { isopropyl }}\right) .{ }^{13} \mathrm{C}$ NMR $\left(\mathrm{CDCl}_{3}, 75 \mathrm{MHz}\right) \delta(\mathrm{ppm}) ; 117.6(\mathrm{CN}), 103.4\left(\mathrm{C}_{1}\right), 86.2\left(\mathrm{C}_{3}\right), 83.6\left(\mathrm{C}_{2}\right), 79.1$ $\left(\mathrm{C}_{4}\right), 74.4\left(\mathrm{C}_{5}\right)$, 71.2, 71.3, 69.3, 62.3, 60.6, 60.3, 60.2, 59.1, 58.3, 42.9, 24.6, 24.5, 24.4, 20.2. HRMS (ES ${ }^{+}$) Calcd. for $\mathrm{C}_{21} \mathrm{H}_{41} \mathrm{~N}_{2} \mathrm{O}_{8} \mathrm{PNa}(\mathrm{M}+\mathrm{Na})$ : 503.2498, found; 503.2483.

\section{2-Benzyloxyethyl 2,3,6-tri- $O$-acetyl-4- $O$-(2,3,4,6-tetra- $O$-acetyl- $\beta$ - D- glucopyranosyl)- $\beta$-D-glucopyranoside (7)}

To a solution of the heptaacetyl cellobiose trichloroacetimidate $\mathbf{6}^{\mathbf{1}}$ (900 mg, $1.15 \mathrm{mmol}$ ) in anhydrous $\mathrm{CH}_{2} \mathrm{Cl}_{2}(10 \mathrm{~mL})$ and 2-benzyloxyethanol (250 $\left.\mu \mathrm{L}, 1.72 \mathrm{mmol}\right), \mathrm{BF}_{3} . \mathrm{OEt}_{2}$ $(15 \mu \mathrm{l}, 0.11 \mathrm{mmol})$ was then added. After stirring at room temperature for $2 \mathrm{~h}$ under argon atmosphere, $\mathrm{NEt}_{3}(0.1 \mathrm{ml})$ was then added. Solvents were then removed and the crude was purified by silica gel column chromathography using as eluent (Hex-AcOEt, 2:1-2:3) to give 7 (700 mg, $79 \%)$ as a syrup. ${ }^{1} \mathrm{H}$ NMR $\left(\mathrm{CDCl}_{3}, 300 \mathrm{MHz}\right) \delta(\mathrm{ppm}) 7.32$ 7.28 (m, 5H, Ph), 5.19-5.09 (m, 2H, $\left.\mathrm{H}_{3 \mathrm{~A}}, \mathrm{H}_{3 \mathrm{~B}}\right), 5.01$ (t, $\left.1 \mathrm{H}, J=9.6 \mathrm{~Hz}, \mathrm{H}_{4 \mathrm{~B}}\right), 4.93-4.87$ $\left(\mathrm{m}, 2 \mathrm{H}, \mathrm{H}_{2 \mathrm{~A}}, \mathrm{H}_{2 \mathrm{~B}}\right), 4.56\left(2 \mathrm{~d}, 2 \mathrm{H}, J=7.8 \mathrm{~Hz}, \mathrm{H}_{1 \mathrm{~A}}, \mathrm{H}_{1 \mathrm{~B}}\right), 4.54-4.47\left(\mathrm{~m}, 3 \mathrm{H}, \mathrm{OCH}_{2}, \mathrm{H}_{6 \mathrm{~A}}\right)$, 4.35 (dd, $1 \mathrm{H}, J=4.5,12.6 \mathrm{~Hz}, \mathrm{H}_{6 \mathrm{~B}}$ ), 4.10-3.91 (m, 3H, $\mathrm{OCH}_{2}, \mathrm{H}_{6}{ }^{\prime} \mathrm{A}, \mathrm{H}_{6}$ ' $\mathrm{B}$ ), 3.79-3.55 (m, $\left.6 \mathrm{H}, \mathrm{OCH}_{2}, \mathrm{H}_{5 \mathrm{~A}}, \mathrm{H}_{5 \mathrm{~B}}, \mathrm{H}_{4 \mathrm{~A}}\right), 2.09-1.96\left(6 \mathrm{~s}, 21 \mathrm{H} . \mathrm{OCOCH}_{3}\right) .{ }^{13} \mathrm{C} \mathrm{NMR}\left(\mathrm{CDCl}_{3}, 75 \mathrm{MHz}\right)$ 
$\delta(\mathrm{ppm}) 170.5,170.3,170.2,169.8,169.6,169.3,169.0(\mathrm{C}=\mathrm{O}), 138.1$ (Cqarom), 128.4, 127.6, 127.5 (Carom), $100.8\left(\mathrm{C}_{1 \mathrm{~A}}\right), 100.7\left(\mathrm{C}_{1 \mathrm{~B}}\right), 76.4,73.2,72.9,72.6,72.5,71.9$, 71.6, 71.5, 69.2, 69.1, 67.8, 61.8, 61.5, 21.0, 20.8, 20.6, 20.5. HRMS (ES ${ }^{+}$) Calcd. for $\mathrm{C}_{35} \mathrm{H}_{46} \mathrm{O}_{19} \mathrm{Na}(\mathrm{M}+\mathrm{Na})$ : 793.2531, found; 793.2520.

\section{2-Benzyloxyethyl 2,3,6-tri- $O$-methyl-4- $O$-(2,3,4,6-tetra- $O$-methyl- $\beta$ - D- glucopyranosyl)- $\beta$-D-glucopyranoside (8)}

Compound 7 (560 mg, $0.72 \mathrm{mmol})$ was dissolved in dry $\mathrm{MeOH}(10 \mathrm{~mL})$ and $\mathrm{Na}_{2} \mathrm{CO}_{3}$ (23 $\mathrm{mg}, 0.21 \mathrm{mmol}$ ) was then added. The reaction mixture was stirred for $2 \mathrm{~h}$ and IR120 was then added to neutralize. Solvent was then removed and the crude was used for next step without any further purification. To a solution of the crude (300 mg, 0.62 $\mathrm{mmol})$ in anhydrous DMF $(6 \mathrm{~mL})$ at $0^{\circ} \mathrm{C}, \mathrm{NaH}(151 \mathrm{mg}, 6.3 \mathrm{mmol})$ was added. The reaction mixture was stirred for $10 \mathrm{~min}$ and $\mathrm{MeI}(549 \mu \mathrm{L}, 8.81 \mathrm{mmol})$ was then added. After $24 \mathrm{~h}$ stirring at room temperature, 2-propanol was then added dropwise and $\mathrm{NH}_{4} \mathrm{Cl}$ sat $(25 \mathrm{~mL})$. Organic phase was extracted with ethyl acetate $(2 \times 50 \mathrm{~mL})$ and washed with sodium bisulfate solution $(50 \mathrm{~mL})$ and brine $(50 \mathrm{~mL})$. Solvents were then removed and the crude was purified by silica gel column chromathography using as eluent (Hex-AcOEt, 1:1-1:6) to give 8 (300 mg, 84\%) as a syrup. ${ }^{1} \mathrm{H} \mathrm{NMR}\left(\mathrm{CDCl}_{3}, 300\right.$ $\mathrm{MHz}) \delta(\mathrm{ppm})$ 7.08-7.03 (m, 5H, Ph), 4.31 (s, 2H, $\left.\mathrm{CH}_{2} \mathrm{Ph}\right), 4.07$ (2d, 2H, J = 7.8 Hz, $\mathrm{H}_{1 \mathrm{~A}}, \mathrm{H}_{1 \mathrm{~B}}$ ), 3.81-3.74 (m, $\left.1 \mathrm{H}, \mathrm{OCH}_{2}\right), 3.52-3.27$ (m, 23H, $\mathrm{H}_{6 \mathrm{~A}}, \mathrm{H}_{6}{ }^{\prime} \mathrm{A}, \mathrm{OCH}_{2}, \mathrm{H}_{5 \mathrm{~A}} \mathrm{H}_{5 \mathrm{~B}}$, 5xCH $\mathrm{CH}_{3} \mathrm{O}$ ), 3.16-3.09 (m, 7H, 2xCH $\mathrm{CH}_{3} \mathrm{O}, \mathrm{H}_{6 \mathrm{~B}}$ ), 3.03-2.85 (m, 4H, $\mathrm{H}_{6}, \mathrm{~B}, \mathrm{H}_{3 \mathrm{~B}}, \mathrm{H}_{3 \mathrm{~A}}, \mathrm{H}_{4 \mathrm{~A}}$ ), $2.82\left(\mathrm{dd}, 1 \mathrm{H}, J=7.8,9.0 \mathrm{~Hz}, \mathrm{H}_{2 \mathrm{~B}}\right), 2.68\left(\mathrm{t}, 1 \mathrm{H}, J=8.7 \mathrm{~Hz}, \mathrm{H}_{2 \mathrm{~A}}\right) \cdot{ }^{13} \mathrm{C} \mathrm{NMR}\left(\mathrm{CDCl}_{3}, 75\right.$ MHz) $\delta(\mathrm{ppm}) 139.2$ (Cqarom), 129.2, 128.6, 128.5 (Carom), $104.4\left(\mathrm{C}_{1 \mathrm{~A}}\right), 104.1\left(\mathrm{C}_{1 \mathrm{~B}}\right)$, 87.9, 85.4, 85.0, 84.0, 80.3, 78.6, 75.6, 74.1, 72.1, 71.6, 70.3, 69.8, 61.6, 61.5, 61.3, 61.2, 61.1, 60.2, 60.0. HRMS (ES ${ }^{+}$) Calcd. for $\mathrm{C}_{21} \mathrm{H}_{40} \mathrm{O}_{12} \mathrm{Na}(\mathrm{M}+\mathrm{Na})$ : 507.2417, found; 507.2433 .

\section{2-Hydroxyethyl 2,3,6-tri- $O$-methyl-4- $O$-(2,3,4,6-tetra- $O$-methyl- $\beta$-D- glucopyranosyl)- $\beta$-D-glucopyranoside (9)}

A solution of compound $8(300 \mathrm{mg}, 0.52 \mathrm{mmol})$ in ethyl acetate-MeOH $(1: 1,5 \mathrm{~mL})$ and $\mathrm{Pd}(\mathrm{OH})_{2}$ in catalytic amount was stirred under an atmosphere of hydrogen for $24 \mathrm{~h}$. The 
mixture was filtered off over celite and solvents were removed. The crude was purified by silica gel column chromathography using as eluent (Hex-AcOEt, 1:6 $\rightarrow 0: 1$ ) to give 9 (209 $\mathrm{mg}, 83 \%)$ as a syrup. ${ }^{1} \mathrm{H} \mathrm{NMR}\left(\mathrm{CDCl}_{3}, 500 \mathrm{MHz}\right) \delta(\mathrm{ppm})$ 4.24-4.22 (2d, $2 \mathrm{H}, J=$ $\left.7.8 \mathrm{~Hz}, \mathrm{H}_{1 \mathrm{~A}}, \mathrm{H}_{1 \mathrm{~B}}\right), 3.85-3.77\left(\mathrm{~m}, 2 \mathrm{H}, \mathrm{OCH}_{2}\right), 3.68-3.52\left(\mathrm{~m}, 16 \mathrm{H}, \mathrm{H}_{6 \mathrm{~A}}, \mathrm{H}_{6}{ }^{\prime}, \mathrm{OCH}_{2}\right.$, $\left.\mathrm{H}_{6 \mathrm{~B}}, \mathrm{H}_{6}{ }^{\prime} \mathrm{B}, \mathrm{H}_{4 \mathrm{~B}}, 3 \mathrm{xCH}_{3} \mathrm{O}\right), 3.49,3.47$ (2s, $\left.6 \mathrm{H}, 2 \mathrm{xCH}_{3} \mathrm{O}\right), 3.40-3.38\left(\mathrm{~m}, 1 \mathrm{H}, \mathrm{H}_{5 \mathrm{~B}}\right), 3.22-$ $3.06\left(\mathrm{~m}, 5 \mathrm{H}, \mathrm{H}_{5 \mathrm{~A}}, \mathrm{H}_{3 \mathrm{~B}}, \mathrm{H}_{3 \mathrm{~A}}, \mathrm{H}_{4 \mathrm{~A}}, \mathrm{OH}\right), 3.00\left(\mathrm{dd}, 1 \mathrm{H}, J=7.8,9.0 \mathrm{~Hz}, \mathrm{H}_{2 \mathrm{~B}}\right), 2.68(\mathrm{t}, 1 \mathrm{H}, J$ $\left.=8.7 \mathrm{~Hz}, \mathrm{H}_{2 \mathrm{~A}}\right) \cdot{ }^{13} \mathrm{C} \mathrm{NMR}\left(\mathrm{CDCl}_{3}, 125 \mathrm{MHz}\right) \delta\left(\mathrm{ppm} 103.8\left(\mathrm{C}_{1 \mathrm{~A}}\right), 103.1\left(\mathrm{C}_{1 \mathrm{~B}}\right), 86.9\right.$, 85.5, 84.0, 83.1, 79.2, 77.9, 74.6, 74.3, 73.4, 71.1, 70.8, 62.3, 60.7, 60.5, 60.4, 60.3, 60.2, 59.2, 59.0. HRMS $\left(\mathrm{ES}^{+}\right)$Calcd. for $\mathrm{C}_{21} \mathrm{H}_{40} \mathrm{O}_{12} \mathrm{Na}(\mathrm{M}+\mathrm{Na})$ : 507.2417, found; 507.2433 .

\section{2-[(2,3,4,6-Tetra- $O$-methyl- $\beta$-D-glucopyranosyl-(1 $\rightarrow 4)-2,3,6$-tri- $O$-methyl- $\beta$-D-} glucopyranosyloxy)]ethyl (2-cyanoethyl) $(N, N$-diisopropyl) phosphoramidite (10)

DIPEA (115 $\mu \mathrm{L}, \quad 0.66 \quad \mathrm{mmol})$ and 2-cyanoethyl-N,N'-diisopropylaminochlorophosphoramidite $(55 \mu \mathrm{L}, 0.24 \mathrm{mmoL})$ were added to a solution of compound 9 (80 mg, $0.16 \mathrm{mmol})$ in anhydrous $\mathrm{CH}_{2} \mathrm{Cl}_{2}(3 \mathrm{~mL})$ at room temperature under an argon atmosphere. After $1.0 \mathrm{~h}$ no starting material was observed. Solvent was then removed and the crude was purified by silica gel column chromatography by using Hex/EtOAc (1:2 with $5 \%$ of $\left.\mathrm{NEt}_{3}\right)$ to give compound $10(100 \mathrm{mg}, 88 \%)$ as a syrup. ${ }^{1} \mathrm{H}$ NMR $\left(\mathrm{CDCl}_{3}, 300 \mathrm{MHz}\right) \delta(\mathrm{ppm}) 4.25-4.20\left(\mathrm{~m}, 2 \mathrm{H}, \mathrm{H}_{1 \mathrm{~A}}, \mathrm{H}_{1 \mathrm{~B}}\right), 3.95-3.41\left(\mathrm{~m}, 27 \mathrm{H}, \mathrm{H}_{6 \mathrm{~A}}, \mathrm{H}_{6 \mathrm{~B}}\right.$, $\left.\mathrm{H}_{6}{ }^{\prime} \mathrm{A}, 2 \mathrm{xOCH}_{2}, \mathrm{OCH}_{2} \mathrm{CH}_{2} \mathrm{CN}, 2 \mathrm{xCH}_{\text {isopropyl }}, \mathrm{H}_{6}{ }^{\prime} \mathrm{B}, 5 \mathrm{xCH}_{3} \mathrm{O}\right), 3.34-3.30\left(\mathrm{~m}, 7 \mathrm{H}, \mathrm{H}_{5 \mathrm{~B}}\right.$,

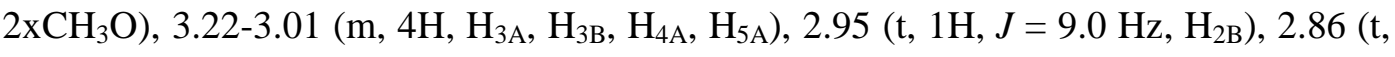
$\left.1 \mathrm{H}, J=9.0 \mathrm{~Hz}, \mathrm{H}_{2 \mathrm{~A}}\right), 2.22-2.39\left(\mathrm{~m}, 2 \mathrm{H}, \mathrm{C}_{2} \mathrm{CN}\right), 1.09$ (d, $\left.12 \mathrm{H}, J=6.5 \mathrm{~Hz}, 4 \mathrm{CH}_{3 \text { isopropyl }}\right)$. ${ }^{13} \mathrm{C} \mathrm{NMR}\left(\mathrm{CDCl}_{3}, 75 \mathrm{MHz}\right) \delta(\mathrm{ppm}) 117.9(\mathrm{CN}), 103.5\left(\mathrm{C}_{1 \mathrm{~A}}\right), 103.1\left(\mathrm{C}_{1 \mathrm{~B}}\right), 86.9,84.3$, 84.0, 83.0, 79.3, 77.5, 74.6, 71.1, 70.5, 69.4, 60.7, 60.6, 60.4, 60.3, 60.2, 59.3, 59.0, 58.4, 43.0, 24.7, 24.6, 24.5, 20.3. HRMS (ES ${ }^{+}$Calcd. for $\mathrm{C}_{28} \mathrm{H}_{46} \mathrm{O}_{12} \mathrm{Na}(\mathrm{M}+\mathrm{Na})$ : 597.2887, found; 597.2882. 
S25 
Proton and carbon NMR spectra of compounds 2-5 and 7-10.
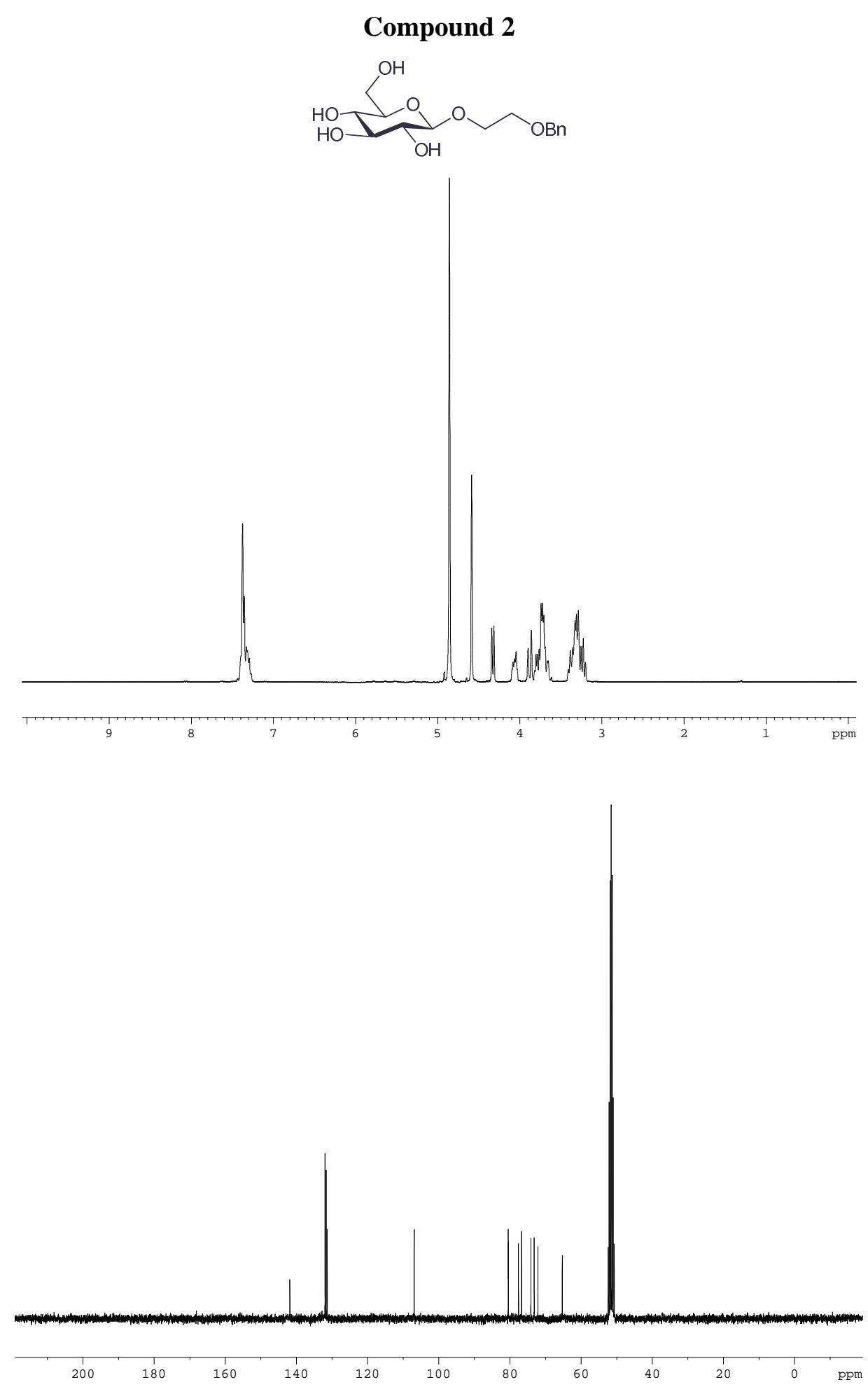

Compound 3 

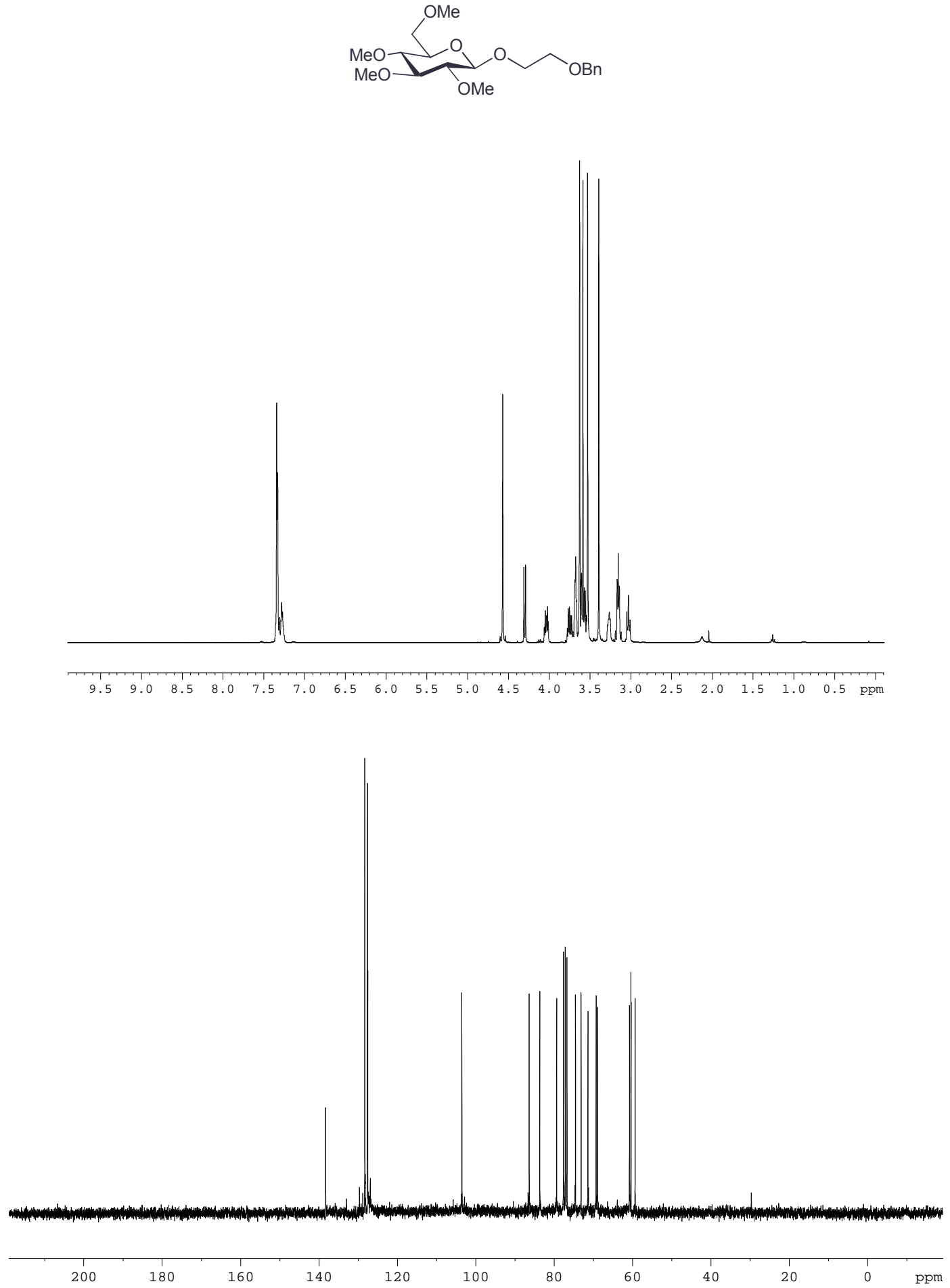

Compound 4 

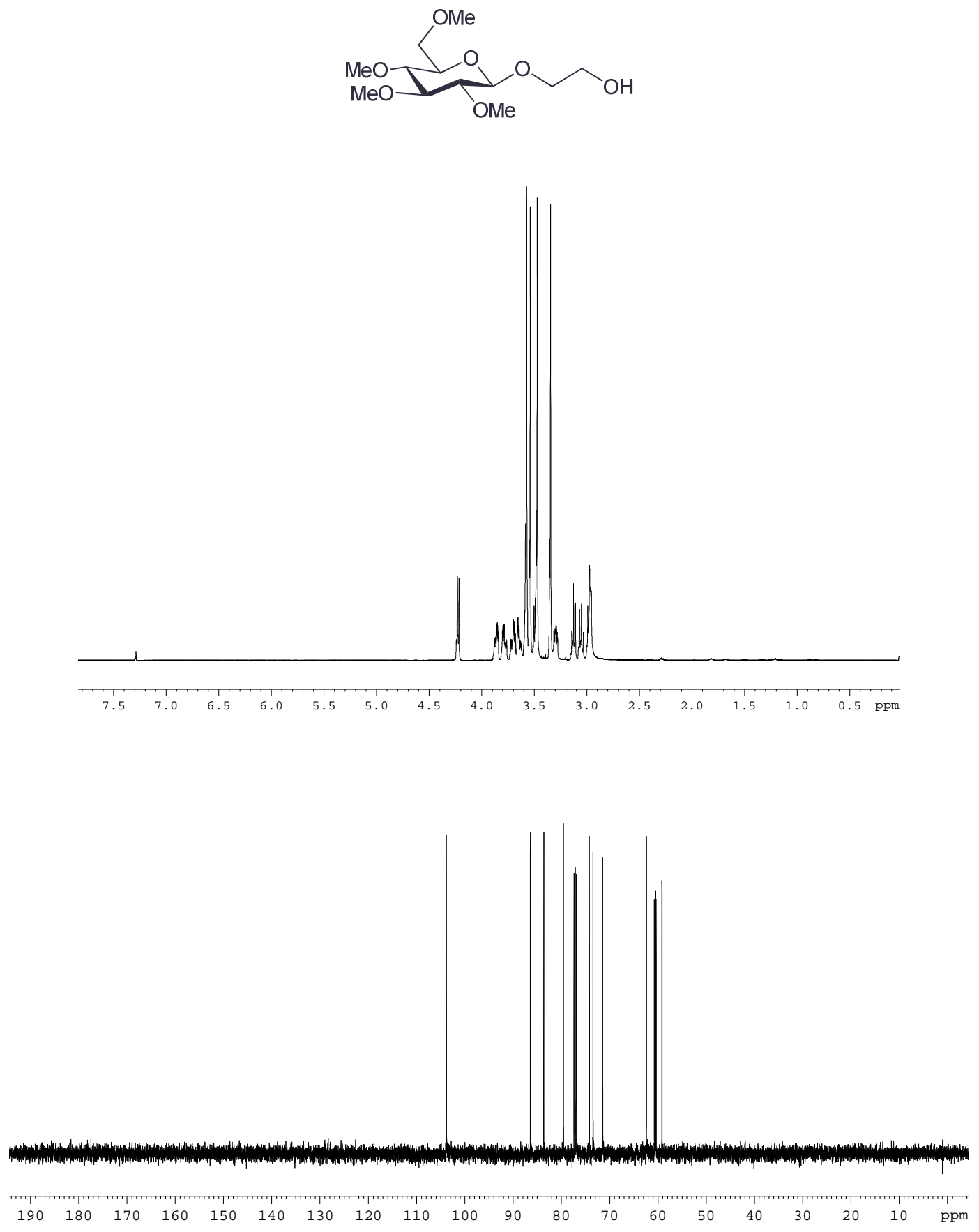

\section{Compound 5}

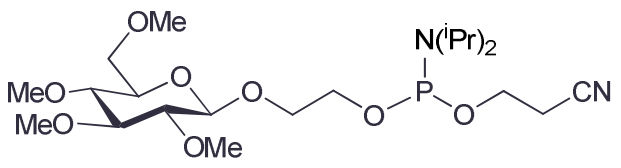



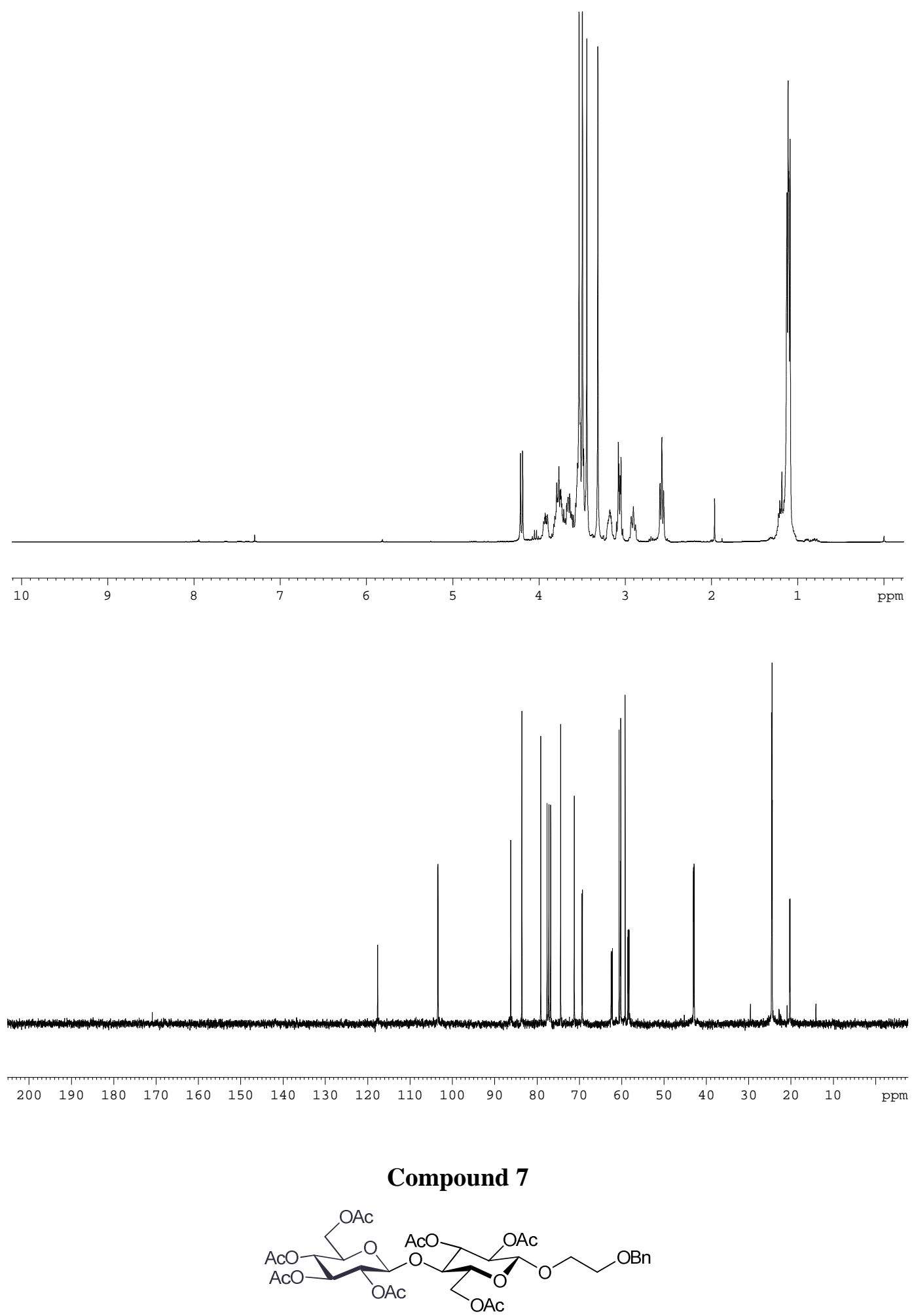

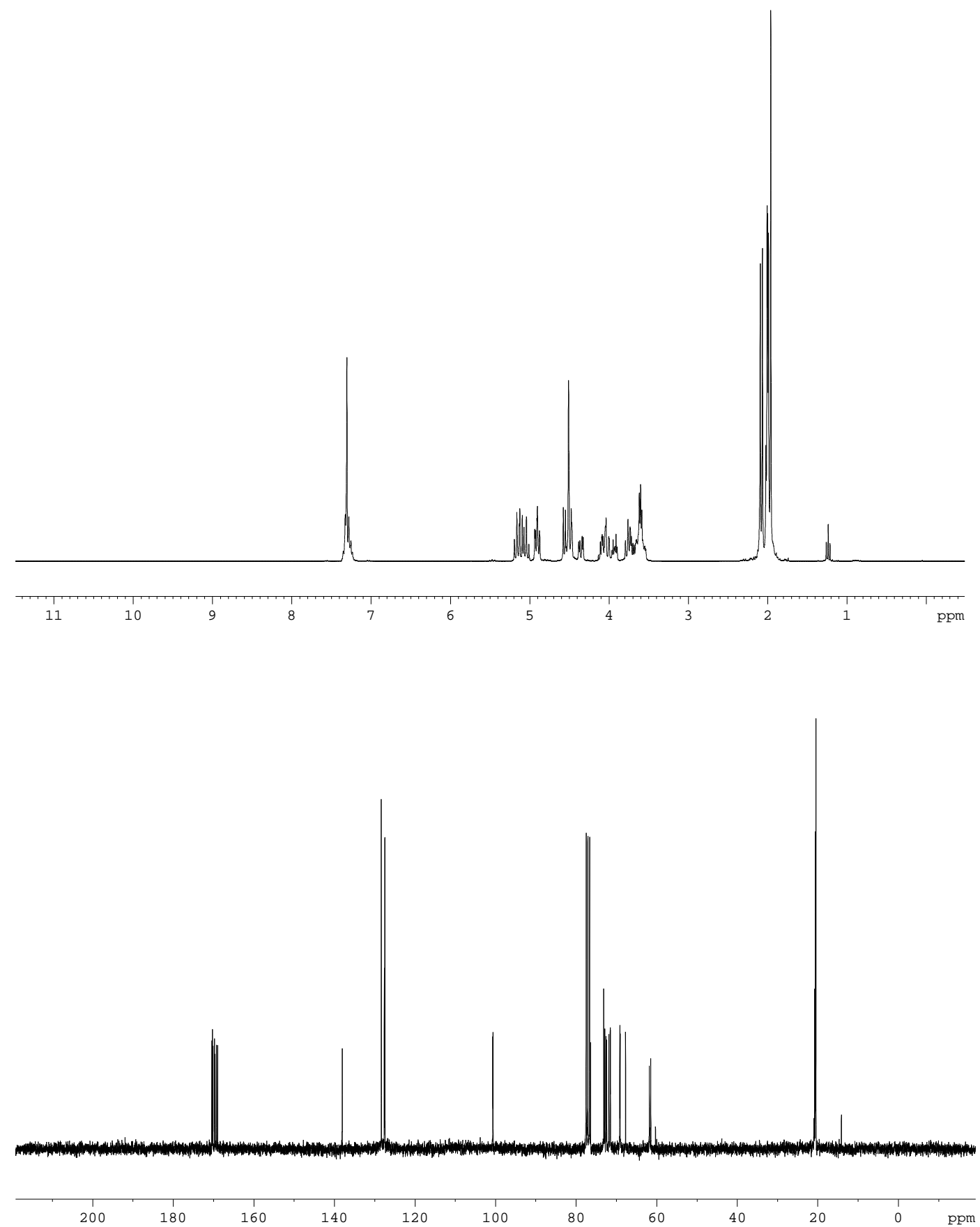

\section{Compound 8}

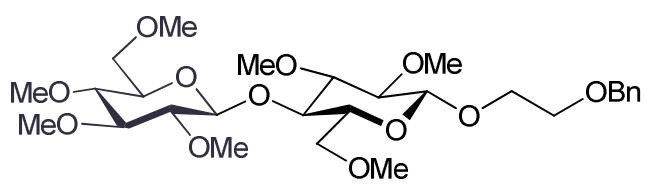



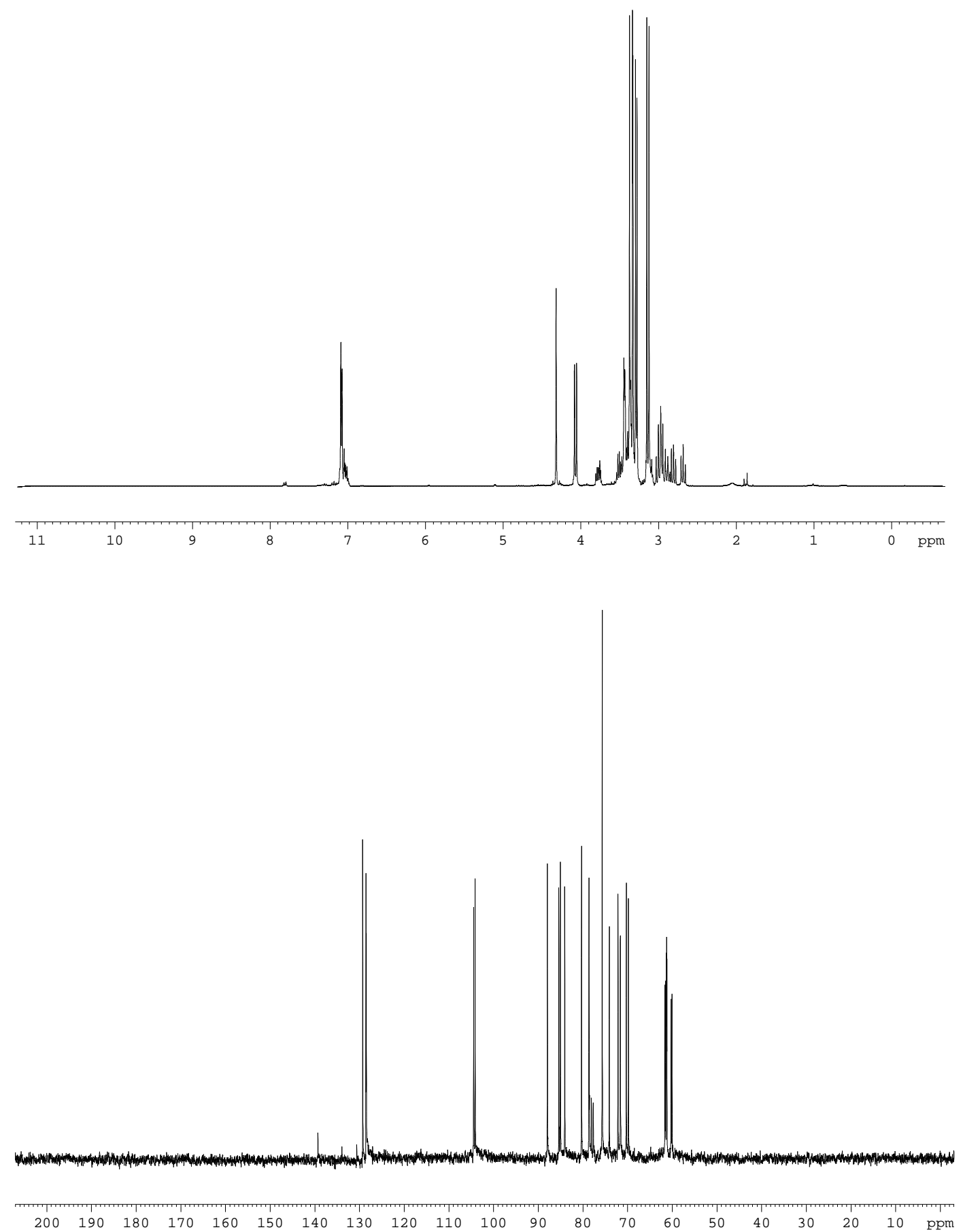

\section{Compound 9}

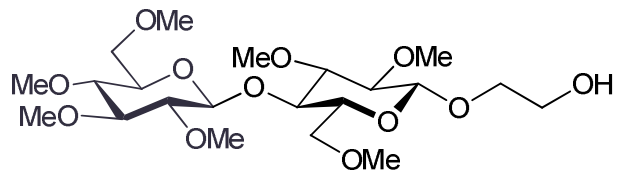



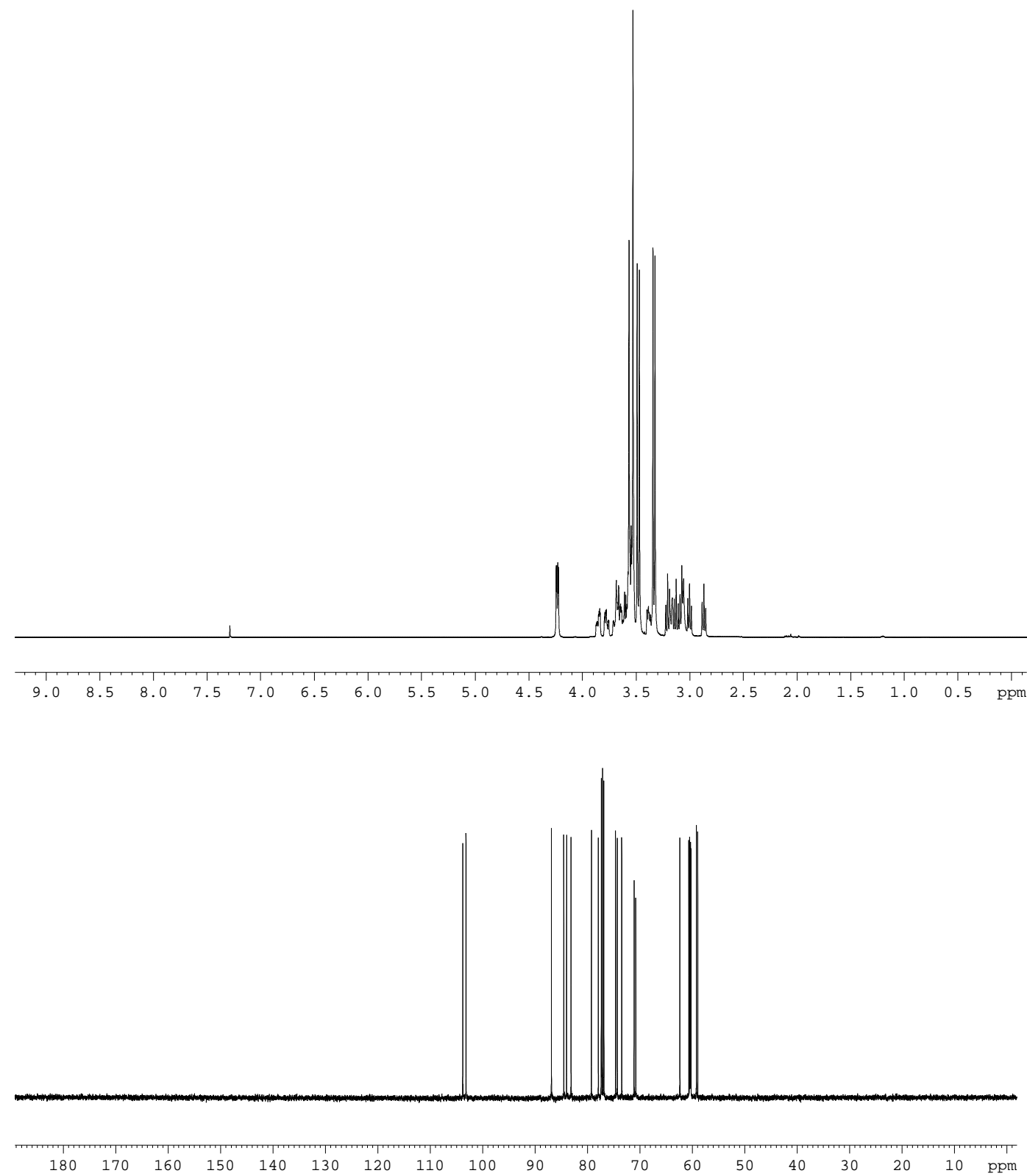

\section{Compound 10}

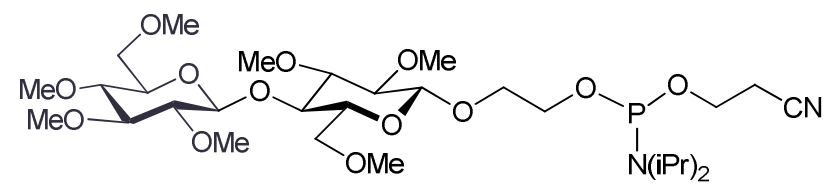



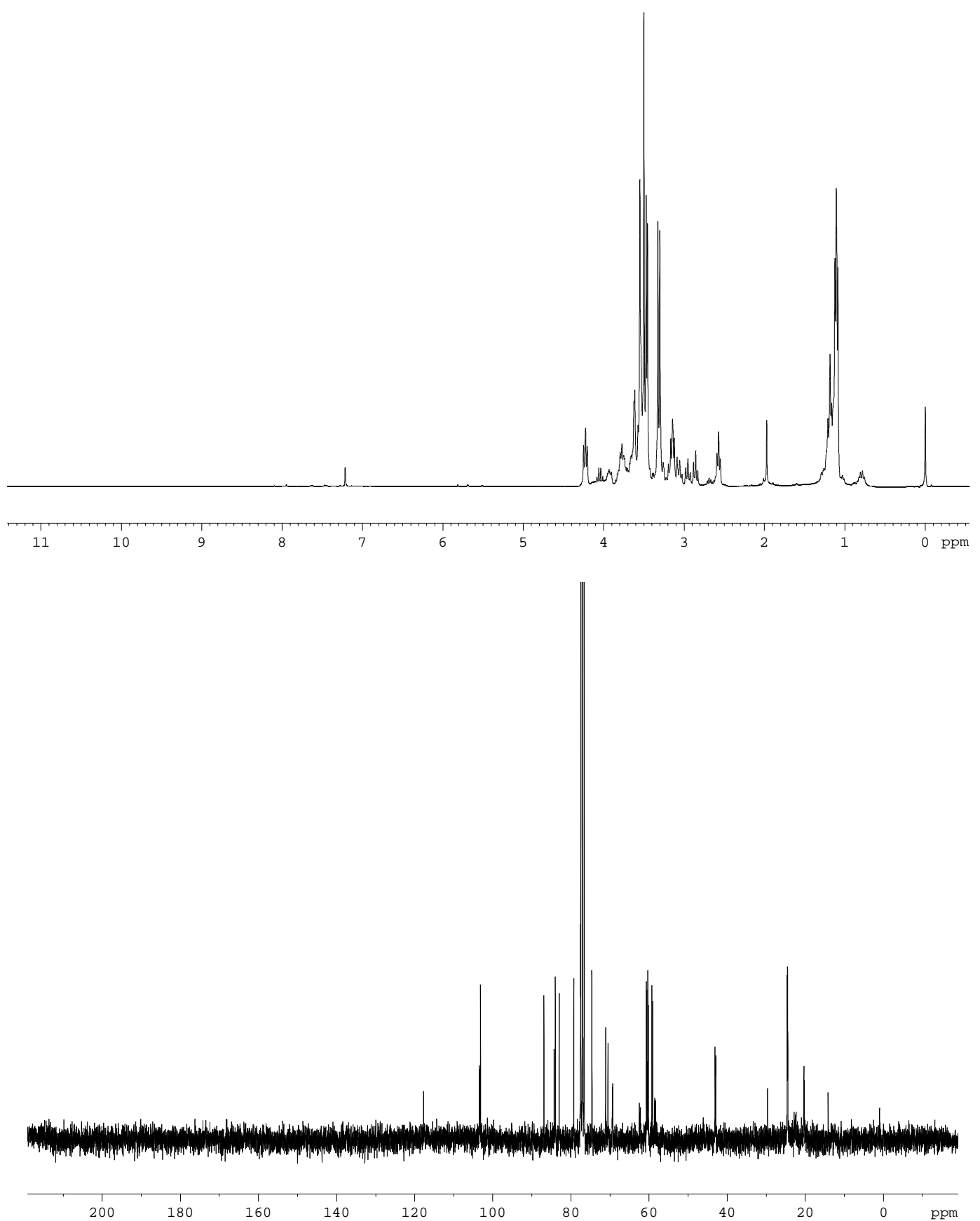


\section{Synthesis of carbohydrate-oligonucleotide conjugates}

Carbohydrate-oligonucleotide conjugates 15, 16, 19 and 20 were synthesized on an Applied Biosystems 394 synthesizer by using standard $\beta$-cyanoethylphosphoramidite chemistry. Conjugate 19, 20, 25, 26, 29 and 30 were prepared by Biomers following the same methodology. Oligonucleotide conjugates were synthesized either on low-volume 200 nmols (LV200) or $1.0 \mu \mathrm{mol}$ scale and using the DMT-off procedure. Oligonucleotide supports were treated with $33 \%$ aqueous ammonia for $16 \mathrm{~h}$ at $55^{\circ} \mathrm{C}$, then the ammonia solutions were evaporated to dryness and the conjugates were purified by reversed-phase HPLC in a Waters Alliance separation module with a PDA detector. HPLC conditions were as follows: Nucleosil $120 \mathrm{C} 18,250 \mathrm{x} 8 \mathrm{~mm}, 10 \mu \mathrm{m}$ column; flow rate: $3 \mathrm{~mL} / \mathrm{min}$. A 27 min linear gradient 0-30\%B (solvent A: 5\% $\mathrm{CH} 3 \mathrm{CN} / 95 \% 100 \mathrm{mM}$ triethylammonium acetate (TEAA; $\mathrm{pH}$ 6.5); solvent B: 70\% CH3CN/30\% 100 mM TEAA (pH 6.5)).

\section{Thermodynamic measurements}

Self-complementary oligonucleotides and COCs were hybridized by heating the sample at $90^{\circ} \mathrm{C}$ for $3 \mathrm{~min}$ and letting cool down to room temperature during $3 \mathrm{~h}$. Melting curves for the DNA conjugates were measured in a Perkin-Elmer Lambda $750 \mathrm{UV} / \mathrm{V}$ is spectrophotometer at $280 \mathrm{~nm}$ while the temperature was raised from 10 to $80{ }^{\circ} \mathrm{C}$ at a rate of $1.0^{\circ} \mathrm{Cmin}-1$. Curve fits were excellent, with c2 values of $10^{6}$ or better, and the Van't Hoff linear fits were quite good $\left(r^{2}=0.97\right)$ for all oligonucleotides. Thermodynamic parameters were calculated from the average values obtained from melting curve fitting (using Meltwin software) and linear Van't Hoff plots of 1/Tm vs $1 \mathrm{n}$ ([conjugate]). $\Delta \mathrm{H}, \Delta \mathrm{S}$, and $\Delta \mathrm{G}$ errors were calculated as described previously. ${ }^{2,3}$ 
HPLC chromatograms of carbohydrate oligonucleotide conjugates 15, 16, 18, 19 and 20.
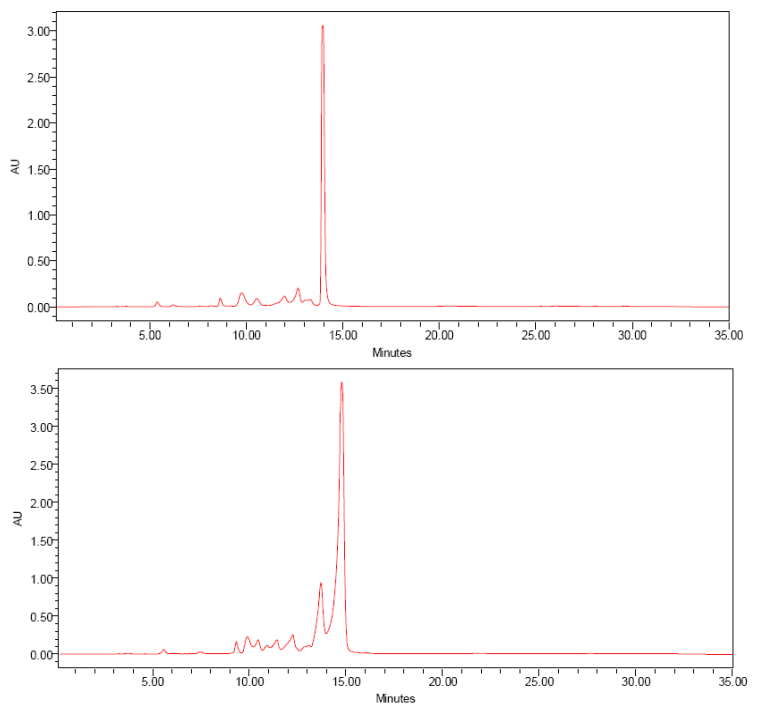

Conjugate glc(Me)-C2-CGCGCG (15)

Conjugate glc(Me)-C2-AGCGCT (16)

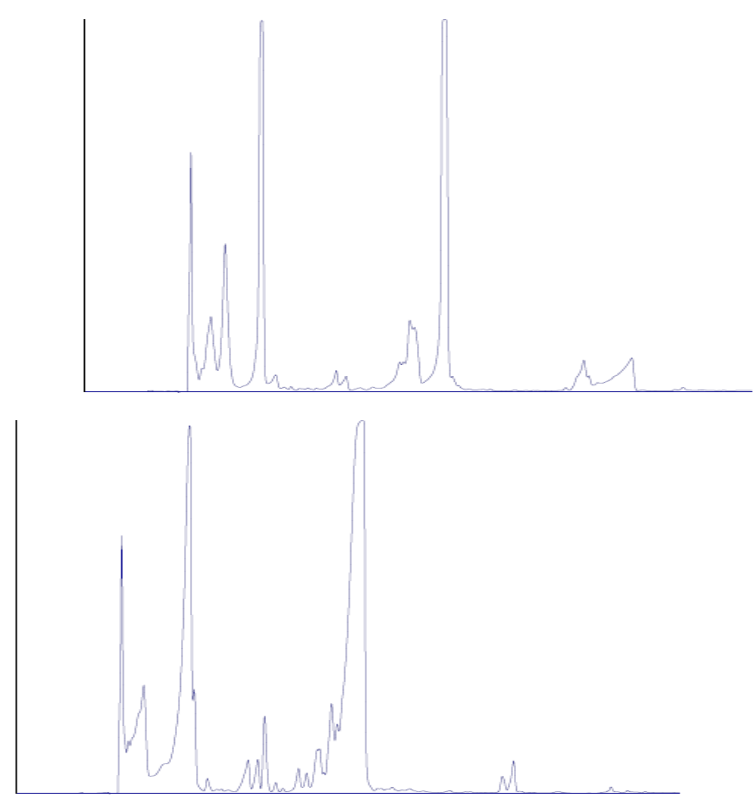

Conjugate cellob(Me)-C2-CGCGCG (19)

(20) 


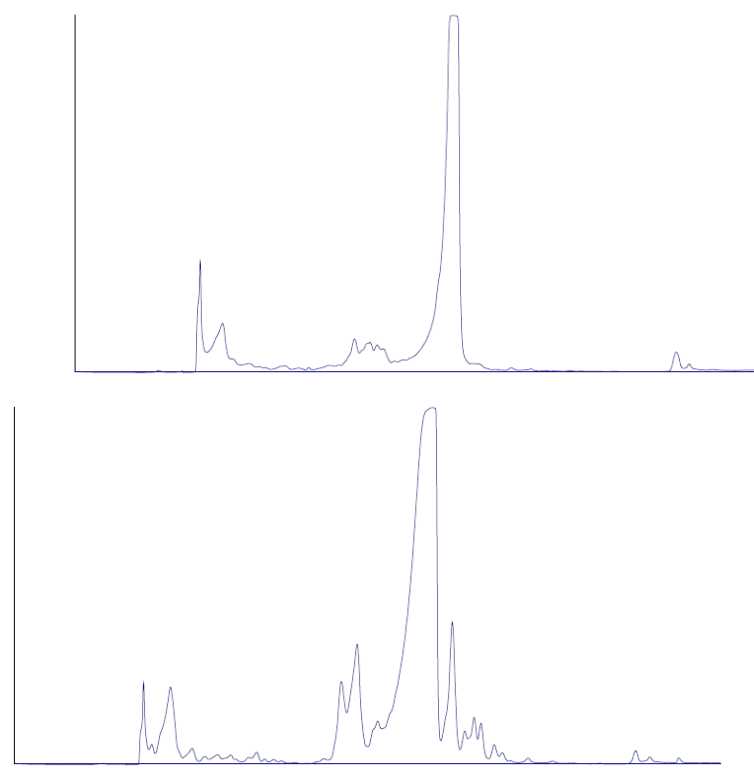

Conjugate glc(Me)-C2-GGCGCC (25)

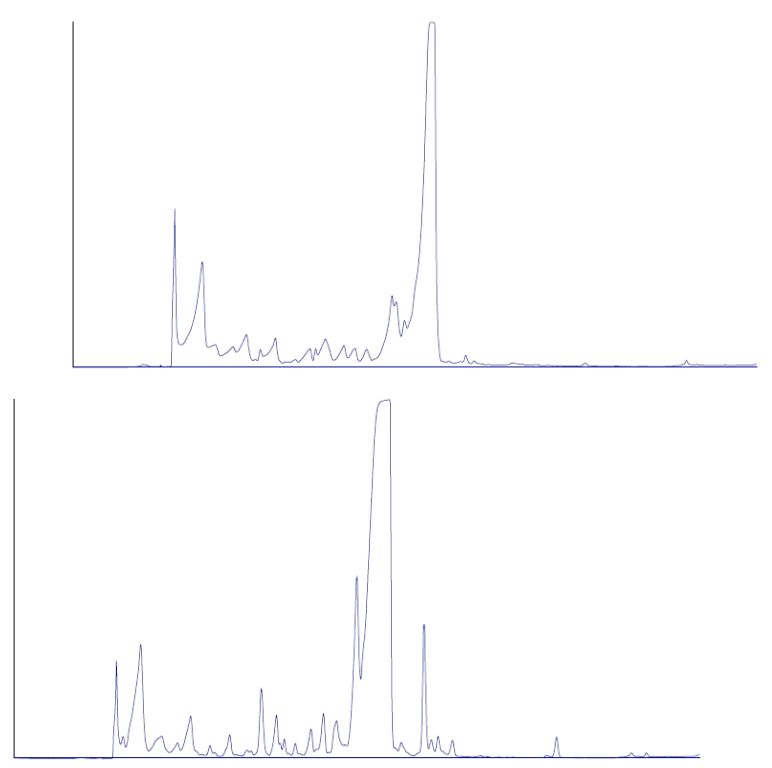

Conjugate cellob(Me)-C2-GGCGCC (29)
Conjugate glc(Me)-C2-TGCGCA (26)

Conjugate cellob(Me)-C2-TGCGCA

(30)

Maldi-TOF mass spectra of carbohydrate oligonucleotide conjugates.

MALDI-TOF spectra were performed using a Perseptive Voyager DETMRP mass spectrometer, equipped with nitrogen laser at $337 \mathrm{~nm}$ using a 3ns pulse. The matrix used contained 2,4,6-trihydroxyacetophenone (THAP, $10 \mathrm{mg} / \mathrm{ml}$ in ACN/ water 1:1) and ammonium citrate $(50 \mathrm{mg} / \mathrm{ml}$ in water $)$. 


\begin{tabular}{|c|c|c|}
\hline $\begin{array}{c}\text { Carbohydrate oligonucleotide } \\
\text { conjugates }\end{array}$ & {$[\mathrm{M}-\mathrm{H}]$ calc. } & {$[\mathrm{M}-\mathrm{H}] \exp$.} \\
\hline$\beta$-D-glc(Me)-C2-CGCGCG (15) & 2133.5 & 2133.5 \\
\hline$\beta$-D-glc(Me)-C2-AGCGCT (16) & 2132.5 & 2132.5 \\
\hline$\beta$-D-cellob(Me)-C2-CGCGCG (19) & 2338.3 & 2339.0 \\
\hline$\beta$-D-cellob(Me)-C2-AGCGCT (20) & 2337.3 & 2337.0 \\
\hline$\beta$-D-glc(Me)-C2-GGCGCC (25) & 2133.5 & 2142.0 \\
\hline$\beta$-D-glc(Me)-C2-TGCGCA (26) & 2132.5 & 2140.0 \\
\hline$\beta$-D-cellob(Me)-C2-GGCGCC (29) & 2338.3 & 2344.0 \\
\hline$\beta$-D-cellob(Me)-C2-TGCGCA (30) & 2337.3 & 2342.0 \\
\hline
\end{tabular}

\section{NMR spectroscopy and structure calculations.}

Samples of the conjugates were purified by HPLC, ion-exchanged with Dowex 50W resin and then suspended in $500 \mu \mathrm{L}$ of either $\mathrm{D}_{2} \mathrm{O}$ or $\mathrm{H}_{2} \mathrm{O} / \mathrm{D}_{2} \mathrm{O} 9: 1$ in phosphate buffer, $100 \mathrm{mM} \mathrm{NaCl}, \mathrm{pH}$ 7. NMR spectra were acquired in Bruker Avance spectrometers operating at 600 or $800 \mathrm{MHz}$, and processed with Topspin software. DQF-COSY, TOCSY and NOESY (mixing times of 150 and 300ms) experiments were recorded in $\mathrm{D}_{2} \mathrm{O}$ at temperatures ranging from $5{ }^{\circ} \mathrm{C}$ to $25^{\circ} \mathrm{C}$. NOESY spectra in $\mathrm{H}_{2} \mathrm{O}$ were acquired with $100 \mathrm{~ms}$ mixing time at $5{ }^{\circ} \mathrm{C}$ to reduce the exchange with water. The spectral analysis program Sparky ${ }^{4}$ was used for semiautomatic assignment of the NOESY crosspeaks and quantitative evaluation of the NOE intensities. Distance constraints with their corresponding error bounds were incorporated into the $\mathrm{AMBER}^{5}$ potential energy by defining a flat-well potential term. Restrained molecular dynamics calculations were carried out following protocols described in our previous study. ${ }^{6}$ The structures were refined including explicit solvent, periodic boundary conditions and the Particle-MeshEwald method to evaluate long-range electrostatic interactions. Force field parameters for the carbohydrate moieties were taken from $\mathrm{GLYCAM}^{7}$, and the TIP3P model was used to describe water molecules. ${ }^{8}$ Analysis of the representative structures as well as the MD trajectories was carried out with the program MOLMOL ${ }^{9}$ and the analysis tools of AMBER. 


\section{References}

1. R. R. Schmidt and J. Michel, Angew. Chem. Int. Ed., 1980, 19, 731-732.

2. $\quad$ S. G. Lokhov and D. V. Pyshnyi, FEBS letters, 1997, 420, 134-138.

3. T. Ohmichi, S. Nakano, D. Miyoshi and N. Sugimoto, Journal of the American Chemical Society, 2002, 124, 10367-10372.

4. D. T. Goddard and G. Kneller, University of California, San Francisco.

5. D. A. Case, D. A. Pearlman, J. W. Caldwell, T. E. C. III, W. S. Ross, C. L. Simmerling, T. A. Darden, K. M. Merz, R. V. Stanton, A. L. Cheng, J. J.

Vincent, M. Crowley, D. M. Ferguson, R. J. Radmer, G. L. Seibel, U. C. Singh, P. K. Weiner and P. A. Kollman, University of California, San Francisco, 1997.

6. R. Lucas, I. Gómez-Pinto, A. Avinnó, J. J. Reina, R. Eritja, C. González and J. C. Morales, Journal of the American Chemical Society, 2011, 133, 1909-1916.

7. R. J. Woods, R. A. Dwek, C. J. Edge and D. Fraser-Reid, J. Phys. Chem., 1995, 99, 3832-3839.

8. W. L. Jorgensen, J. Chandrasekhar, J. D. Madura, R. W. Impey and M. L. Klein, J. Chem. Phys., 1983, 79, 926-935.

9. R. Koradi, M. Billeter and K. Wuthrich, J. Mol. Graphics, 1996, 14, 29-32. 